\title{
Effects of Arctic geoengineering on precipitation in the tropical monsoon regions
}

\author{
Aditya Nalam $^{1}\left[\right.$ [ $\cdot$ Govindasamy Bala $^{1} \cdot$ Angshuman Modak $^{1}$
}

Received: 28 November 2016 / Accepted: 13 July 2017 / Published online: 27 July 2017

(C) The Author(s) 2017. This article is an open access publication

\begin{abstract}
Arctic geoengineering wherein sunlight absorption is reduced only in the Arctic has been suggested as a remedial measure to counteract the on-going rapid climate change in the Arctic. Several modeling studies have shown that Arctic geoengineering can minimize Arctic warming but will shift the Inter-tropical Convergence Zone (ITCZ) southward, unless offset by comparable geoengineering in the Southern Hemisphere. In this study, we investigate and quantify the implications of this ITCZ shift due to Arctic geoengineering for the global monsoon regions using the Community Atmosphere Model version 4 coupled to a slab ocean model. A doubling of $\mathrm{CO}_{2}$ from pre-industrial levels leads to a warming of $\sim 6 \mathrm{~K}$ in the Arctic region and precipitation in the monsoon regions increases by up to $\sim 15 \%$. In our Arctic geoengineering simulation which illustrates a plausible latitudinal distribution of the reduction in sunlight, an addition of sulfate aerosols (11 Mt) in the Arctic stratosphere nearly offsets the Arctic warming due to $\mathrm{CO}_{2}$ doubling but this shifts the ITCZ southward by $\sim 1.5^{\circ}$ relative to the pre-industrial climate. The combined effect from this shift and the residual $\mathrm{CO}_{2}$-induced climate change in the tropics is a decrease/increase in annual mean precipitation in the Northern Hemisphere/Southern Hemisphere monsoon regions by up to $-12 /+17 \%$. Polar geoengineering where sulfate aerosols are prescribed in both the Arctic $(10 \mathrm{Mt})$ and Antarctic $(8 \mathrm{Mt})$ nearly offsets the ITCZ shift
\end{abstract}

Electronic supplementary material The online version of this article (doi:10.1007/s00382-017-3810-y) contains supplementary material, which is available to authorized users.

Aditya Nalam

aditya.nalam@gmail.com

1 Centre for Atmospheric and Oceanic Sciences, Indian Institute of Science, Bangalore 560012, India due to Arctic geoengineering, but there is still a residual precipitation increase (up to 7\%) in most monsoon regions associated with the residual $\mathrm{CO}_{2}$ induced warming in the tropics. The ITCZ shift due to our Global geoengineering simulation, where aerosols $(20 \mathrm{Mt})$ are prescribed uniformly around the globe, is much smaller and the precipitation changes in most monsoon regions are within $\pm 2 \%$ as the residual $\mathrm{CO}_{2}$-induced warming in the tropics is also much less than in Arctic and Polar geoengineering. Further, global geoengineering nearly offsets the Arctic warming. Based on our results we infer that Arctic geoengineering leads to ITCZ shift and leaves residual $\mathrm{CO}_{2}$ induced warming in the tropics resulting in substantial precipitation decreases (increases) in the Northern (Southern) hemisphere monsoon regions.

Keywords Arctic geoengineering - Stratospheric sulfate aerosols · ITCZ shift · Global monsoon regions . Stratospheric climate change

\section{Introduction}

Unabated increase in greenhouse gas emissions is warming the planet, and this warming is amplified in the polar regions. This larger warming in the polar regions is known as polar amplification and occurs mostly due to the icealbedo, temperature and water vapor feedbacks that operate strongly at higher latitudes (Collins et al. 2013; Pithan and Mauritsen 2014). Polar amplification is robustly seen in climate model simulations of climate change (Holland and Bitz 2003) and has also been observed in late twentieth century data (Vaughan et al. 2013; Stroeve et al. 2012). The main effects of polar climate change such as rapid sea ice loss, damaged ecological systems, accelerated 
melting of Greenland and Antarctic ice sheets, increased risk of extreme events and permafrost thawing are already observed in the Arctic and are likely to reach tipping points (Duarte et al. 2012). It is likely that the Arctic ocean could be ice free during summer by 2050 , and will probably have effects on the northern mid-latitudes shifting the jetstreams and storm tracks (Duarte et al. 2012). In the context of countering the impact of this rapid climate change in the Arctic, the Arctic Council discussed some regional geoengineering options (Duarte et al. 2012).

Geoengineering is an intentional manipulation of the climate system to reduce the undesired impacts of climate change caused by increasing greenhouse gases (Keith 2000; Shephard et al. 2009; IPCC 2014). Geoengineering by injecting sulfate aerosols into stratosphere was first suggested by Budkyo (1974). These injected aerosols would increase the planetary albedo, thereby reducing the incoming solar radiation at the surface and counteract the greenhouse warming. These aerosols could also affect the UV flux into the troposphere, affecting the atmospheric chemistry. Crutzen (2006) advocated research into climate geoengineering since $\mathrm{CO}_{2}$ emission reductions were not taking place. Early modeling research in geoengineering showed that solar geoengineering schemes could markedly diminish regional and seasonal climate change caused by increase in $\mathrm{CO}_{2}$ concentration (Govindasamy and Caldeira 2000; Govindasamy et al. 2003). In the recent past, several modeling studies have investigated solar geoengineering using stratospheric sulfate aerosols (Robock et al. 2008; Modak and Bala 2014; Tilmes et al. 2009; Pitari et al. 2014; Niemeier and Timmreck 2015). Other geoengineering methods such as marine cloud brightening and ocean albedo modification are also discussed in detail in several reviews (Bala 2009; Lenton and Vaughn 2009; Caldeira et al. 2013; NRC Report 2015).

In contrast to global scale geoengineering proposals, regional geoengineering proposals target intervention on selected regions such as the Arctic. Climate interventions in the Arctic are generally suggested as an interim endeavour to reduce the polar amplification while global emissions are reduced in order to bring overall global warming under control, and not as some independent intervention. In one of the earliest modeling studies on Arctic geoengineeing by Caldeira and Wood (2008), solar irradiance is reduced uniformly across the Arctic region. It is found that a $25 \%$ reduction in solar irradiance from $61^{\circ} \mathrm{N}$ to $90^{\circ} \mathrm{N}$ would restore the climate in the Arctic region. However, there is a residual global mean warming present in the regions outside the Arctic. This study further finds that Arctic geoengineering could reduce Arctic amplification by more snow accumulation in the Arctic and thus moderate the sea-level rise. Tilmes et al. (2014) shows that summer Arctic seaice can be saved by solar irradiance reduction only in the
Arctic but it would require four times more reduction in the Arctic than a simulation with globally uniform reduction. Jackson et al. (2015) show that controllability of Arctic seaice extent can be achieved by making annual adjustments to $\mathrm{SO}_{2}$ injection in the Arctic stratosphere.

Robock et al. (2008) simulated geoengineering by injecting $3 \mathrm{Mt} / \mathrm{a}$ of $\mathrm{SO}_{2}$ at $68^{\circ} \mathrm{N}$ in the lower stratosphere $(10-15 \mathrm{~km})$ to form sulfate aerosols, which did spread poleward, but also spread southward and reached some of the monsoon regions. A larger warming, relative to the scenario without geoengineering, was simulated in Northern India and Africa during summer due to weakening of monsoon circulation and reduction in cloud cover. The weaker monsoon circulation is due to a reduced temperature gradient between Indian Ocean and Asia (Oman et al. 2005; Graf et al. 1992), resulting in a large reduction in summer monsoon precipitation, for India, China, Sahel and Japan.

Haywood et al. (2013) simulated reduced precipitation in Sahel when geoengineering is implemented in the northern hemisphere $(\mathrm{NH})$. Injecting $5 \mathrm{Tg}$ of $\mathrm{SO}_{2}$ in the $\mathrm{NH}$ stratosphere in an RCP 4.5 scenario led to more negative Sahelian precipitation anomalies relative to the 1900-2010 climatology and also resulted in $\sim 60$ to $100 \%$ reduction in Net Primary productivity (NPP) in the Sahel region. In contrast, $\mathrm{SO}_{2}$ injection in the southern hemisphere $(\mathrm{SH})$ stratosphere resulted in more positive Sahelian precipitation anomalies and an increase in NPP by more than $100 \%$. These changes are mainly attributed to a shift in the location of the June-October Inter-tropical Convergence Zone (ITCZ) away from the hemisphere in which geoengineering is implemented.

MacCracken et al. (2013) showed that solar irradiance reduction, when imposed in $\mathrm{NH}$ high latitudes to reduce the Arctic climate change, would lead to a southward shift in ITCZ during both June-July-August (JJA) and December-January-February (DJF) seasons. However, when comparable solar reduction is imposed in both $\mathrm{NH}$ and $\mathrm{SH}$ high latitudes, the position of ITCZ is nearly unaltered. Kravitz et al. (2016) showed that annual mean Arctic temperature and ITCZ location can be adjusted by reducing solar radiation in the Arctic and Antarctic by appropriate amounts.

Apart from ITCZ shifts, previous studies showed that, Arctic geoengineering is associated with residual global and tropical mean warming (Caldeira and Wood 2008; MacCracken et al. 2013). However, uniform global reduction in incoming solar radiation (Govindasamy and Caldeira 2000; Kalidindi et al. 2014; Kravitz et al. 2016) can restore global mean temperatures without shifting the ITCZ (Modak and Bala 2014; Kravitz et al. 2016) but it could overcool the tropics and leave residual warming in the polar regions (Govindasamy et al. 2003). In order to reduce regional anomalies, some studies (Ban-Weiss and Caldeira 2010; MacMartin et al. 2013; Modak and 
Bala 2014; Kravitz et al. 2016) imposed a latitudinal distribution of solar insolation reduction or sulfate aerosol prescription such that the temperature and precipitation anomalies in all latitudes were minimized.

The shifting of ITCZ has been discussed in not only Arctic geoengineering studies, but also in various other studies that investigate the effects of extra-tropical forcing such as high latitude sea ice cover changes (Chiang and Bitz 2005), high latitude volcanic eruptions (Oman et al. 2005; Robock et al. 2008; Haywood et al. 2013), boreal deforestation (Devaraju et al. 2015), high latitude ice sheets corresponding to the glacial periods (Broccoli et al. 2006) and hemispherical asymmetries in clear-sky albedo (Voigt et al. 2014). One of the effects associated with ITCZ shift is the change in cross-equatorial heat transport (Donohoe et al. 2013; Frierson and Hwang 2012). For instance, cooling the high-latitudes of the NH (SH) leads to an increased equator-to-pole heat transport in that hemisphere (translating to an increase (decrease) in cross-equatorial northward heat transport) and a shift in ITCZ away from NH (SH) (MacCracken et al. 2013).

In this paper, we use climate model simulations to study the impacts of Arctic geoengineering on precipitation changes in the global monsoon regions associated with ITCZ shifts caused by the Arctic geoengineering. We address the following research questions: By what magnitude does the ITCZ shift due to Arctic geoengineering and what are the reasons for it? How much compensation in this shift is achieved by geoengineering in both Arctic and Antarctic simultaneously? How large is this ITCZ shift when solar radiation is reduced uniformly around the globe (Global geoengineering)? To what extent is precipitation in the monsoon regions affected due to Arctic, Polar (both Arctic and Antarctic) and Global geoengineering? What are the associated changes in atmospheric heat transport due to Arctic, Polar and Global geoengineering? Among the regional and global geoengineering options attempting to offset Arctic climate change, which option would have smaller effects on precipitation in the tropics?

We address these questions using the National Center for Atmospheric Research (NCAR) climate model Community Atmosphere Model version 4 (CAM4) coupled to a slab ocean model that is briefly discussed in the next section where the experimental design is also presented. In Sect. 3, we first discuss global mean residual climate change in our geoengineering experiments. The ITCZ shifts and the corresponding precipitation changes in monsoon regions and heat transport changes are discussed next. Finally, the implementation of Arctic geoengineering only during summertime is discussed. Discussion and conclusions are presented in Sect. 4.

\section{Model and experiments}

\subsection{Model}

We use the Community Atmosphere Model (CAM4) coupled to the Community Land Model (CLM4) and a Slab Ocean Model for this study. CAM4 Model has 26 vertical atmosphere layers, and for our simulations we used a horizontal resolution of $1.9^{\circ}$ latitude and $2.5^{\circ}$ longitude. We used the finite volume scheme as the dynamical core in CAM4, as it gives improved transport properties (Neale et al. 2010).

CAM4 has $0.6 \mathrm{Mt}$ of background sulfate aerosols in the entire global atmosphere in the form of $\left(\mathrm{NH}_{4}\right)_{2} \mathrm{SO}_{4}$ with fixed size $(0.05 \mu \mathrm{m}, 2.0,0.17 \mu \mathrm{m}$ for dry mode radius, standard deviation, and effective radius, respectively). Several previous studies injected $\mathrm{SO}_{2}$ into stratosphere which later oxidized to form $\mathrm{H}_{2} \mathrm{SO}_{4}$ aerosols (Robock et al. 2008; Haywood et al. 2013; Jackson et al. 2015). Although hygroscopic growth is different for $\left(\mathrm{NH}_{4}\right)_{2} \mathrm{SO}_{4}$ and $\mathrm{H}_{2} \mathrm{SO}_{4}$, their optical properties are similar (Kiehl et al. 2000). Hence, prescribing $\left(\mathrm{NH}_{4}\right)_{2} \mathrm{SO}_{4}$ is similar to injecting $\mathrm{SO}_{2}$ into the stratosphere and oxidizing it. These sulfate aerosols reflect the incoming solar radiation but also absorb near-IR radiation (single scattering albedo is $\sim 0.9$ ). The absorption of terrestrial radiation by sulfate aerosols is not included in CAM4. Amounts of other aerosol species in the model such as dust, organic carbon, black carbon and sea-salt remain the same in all our experiments. All aerosol species, including the additionally prescribed aerosols are not transported, and aerosol indirect effects such as cloud lifetime and cloud albedo modification in the troposphere by the prescribed aerosols are not modelled in our simulations.

The slab ocean model used here considers only the mixed layer of the ocean with no explicitly simulated ocean currents. However, the climatological mean heat transports by these currents are prescribed: deep water heat exchange and poleward ocean heat transport are fixed across the simulations. The spatial pattern of heat transport is obtained from the control run of CESM's fully coupled ocean and atmosphere model (Neale et al. 2010). The thermodynamic sea-ice model adopted in this study uses the mixed layer temperature to update the sea-ice fraction. No ice dynamics is involved in computing the sea-ice extent (Neale et al. 2010).

\subsection{Experiments}

In order to investigate the influence of different geoengineering schemes on the tropical precipitation response and associated changes in ITCZ location, we perform five equilibrium simulations (Table 1): (1) control 'CTL' where the atmospheric $\mathrm{CO}_{2}$ concentration is fixed at pre-industrial 
Table 1 Experiment details

\begin{tabular}{|c|c|c|c|}
\hline Name & Sulfate amount & Constraint for sulfate amount & $\begin{array}{l}\text { Ratio of additional } \\
\text { to naturally present } \\
\text { sulfate amount in } \\
\text { the stratosphere }\end{array}$ \\
\hline CTL & $\begin{array}{l}0.45 \mathrm{Mt} \mathrm{SO}_{4} \text { in troposphere } \\
0.15 \mathrm{Mt} \mathrm{SO}_{4} \text { in stratosphere }\end{array}$ & - & 1 \\
\hline $2 \mathrm{XCO} 2$ & Same as CTL & - & 1 \\
\hline ARCTIC & $\begin{array}{l}\text { Same as CTL, but with } 11 \mathrm{Mt} \text { of additional amount in } \\
\text { the Arctic }\left(50^{\circ} \mathrm{N}-90^{\circ} \mathrm{N}\right) \text { stratosphere }\end{array}$ & $\begin{array}{l}\text { Mean surface temperature anomaly (relative to the } \\
\text { CTL case) from } 60^{\circ} \mathrm{N} \text { to } 90^{\circ} \mathrm{N} \text { is nearly zero }\end{array}$ & 73.3 \\
\hline ARCTIC_S & $\begin{array}{l}\text { Same as ARCTIC, but sulfate prescribed only during } \\
\text { the sunlit months (April-September) }\end{array}$ & $\begin{array}{l}\text { Same amount of aerosols as in ARCTIC but aerosols } \\
\text { are prescribed only during the sunlit months of the } \\
\text { Arctic region }\end{array}$ & 73.3 \\
\hline POLAR & $\begin{array}{l}\text { Same as CTL, but with an additional } 10 \mathrm{Mt} \text { in the } \\
\text { Arctic }\left(50^{\circ} \mathrm{N}-90^{\circ} \mathrm{N}\right) \text { stratosphere and } 8 \mathrm{Mt} \text { in Ant- } \\
\text { arctic }\left(50^{\circ} \mathrm{S}-90^{\circ} \mathrm{S}\right) \text { stratosphere }\end{array}$ & $\begin{array}{l}\text { Mean surface temperature anomaly (relative to the } \\
\mathrm{CTL} \text { case) from } 60^{\circ} \mathrm{N} \text { to } 90^{\circ} \mathrm{N} \text { and from } 60^{\circ} \mathrm{S} \text { to } \\
90^{\circ} \mathrm{S} \text { is nearly zero }\end{array}$ & 120 \\
\hline POLAR_S & $\begin{array}{l}\text { Same as POLAR, but sulfate prescribed only during } \\
\text { sunlit months i.e. April-September in the Arctic and } \\
\text { October-March in the Antarctic }\end{array}$ & $\begin{array}{l}\text { Same amount of aerosols as in POLAR but aerosols } \\
\text { are prescribed only during the sunlit months of the } \\
\text { respective polar regions }\end{array}$ & 120 \\
\hline GLOBAL & $\begin{array}{l}\text { Same as CTL, but with an additional } 20 \mathrm{Mt} \text { in the } \\
\text { stratosphere uniformly spread across the globe }\end{array}$ & $\begin{array}{l}\text { Global mean surface temperature anomaly (relative to } \\
\text { the CTL case) is nearly zero }\end{array}$ & 133.33 \\
\hline
\end{tabular}

$\mathrm{CO}_{2}$ level (284.7 ppmv), (2) '2XCO2' where the atmospheric $\mathrm{CO}_{2}$ concentration is doubled (569.4 ppmv) from its pre-industrial value, (3) 'ARCTIC' which is similar to "2XCO2" but a total amount of $11 \mathrm{Mt}$ of sulfate aerosol is prescribed in the Arctic stratosphere from $50^{\circ} \mathrm{N}$ to North Pole, (4) 'POLAR' which is similar to "ARCTIC" but with prescription of $10 \mathrm{Mt}$ of sulfate aerosols in the Arctic stratosphere from $50^{\circ} \mathrm{N}$ to North Pole and $8 \mathrm{Mt}$ in the Antarctic stratosphere from $50^{\circ} \mathrm{S}$ to South Pole and (5) 'GLOBAL' which is similar to "2XCO2" but with a prescription of a total amount $20 \mathrm{Mt}$ of sulfate aerosols prescribed with uniform concentration across the globe (Table 1). To compare the amounts of sulfate aerosols used in our geoengineering simulations to a major volcanic eruption, it may be noted that the 1991 Pinatubo eruption injected about $20 \mathrm{Mt}$ of $\mathrm{SO}_{2}$ (30 Mt of $\mathrm{SO}_{4}$; Stenchikov et al. 2002) into the stratosphere. Further, it should be noted that we do not inject aerosols in our simulations. Rather, we have prescribed them in all our experiments. Assuming the sulfate aerosol lifetime in the stratosphere is 2 years, the prescription of $20 \mathrm{Mt}$ of sulfate in the stratosphere is equivalent to a Pinatubo eruption every 3 years. The tropospheric aerosols in the ARCTIC, POLAR and GLOBAL simulations are kept unchanged from the CTL case.

In the ARCTIC and POLAR simulations the additional sulfate aerosol concentration is prescribed such that it starts from a zero value at $50^{\circ}$ in each hemisphere and increases smoothly to reach the maximum concentration at the poles; the concentration varies as $0.5+\frac{\sin x}{2}, x \in\left[-\frac{\pi}{2}: \frac{\pi}{2}\right]$ with $\mathrm{x}=-\frac{\pi}{2}$ corresponding to $50^{\circ}$ latitude and $\mathrm{x}=\frac{\pi}{2}$ to the poles
(Fig. 1b, c). The profile used here is a sine curve $\left(\sin \left[\frac{-\pi}{2}: \frac{\pi}{2}\right]\right)$, as it increases and reaches a peak value smoothly, instead of a profile where there is a uniform solar reduction from $61^{\circ} \mathrm{N}$ to $90^{\circ} \mathrm{N}$ and $61^{\circ} \mathrm{S}$ to $90^{\circ} \mathrm{S}$, which could generate a strong cooling effect at the sea-ice edges due to ice-albedo feedback (MacCracken et al. 2013). In all the geoengineeirng simulations (ARCTIC, POLAR and GLOBAL) the additional stratospheric sulfate aerosols are prescribed in the lower stratosphere from 78 to $9.8 \mathrm{hPa}$ with maximum concentration $\sim 30 \mathrm{hPa}$ throughout the year. The constraint for selecting the specific amount of sulfate aerosols in the geoengineering simulations is that the warming in the 2XCO2 simulation in the region where the sulfate aerosols are prescribed should be nearly offset (anomaly relative to the CTL case is within the \pm 1 standard deviation (interannual variability) in the CTL case; Table 1). This constraint was achieved in each geoengineering simulation by performing several trial simulations (lasting a few decades) with different total amount of aerosols.

While it is known that the Antarctic sulfate loading would tend to shift the ITCZ back to its original position (Kravitz et al. 2016), we design the POLAR experiment such that the warming in both Arctic and Antarctic are also offset. Therefore, unlike Kravitz et al. (2016) who design the Antarctic forcing to offset the ITCZ shift due to Arctic geoengineering, we choose Antarctic sulfate forcing to offset the Antarctic warming caused by $\mathrm{CO}_{2}$ doubling. The Arctic region sulfate loading has been reduced from $11 \mathrm{Mt}$ in ARCTIC to $10 \mathrm{Mt}$ in the POLAR case. This is because retaining $11 \mathrm{Mt}$ in the Arctic region for the POLAR case overcools the Arctic surface by $\sim 0.5 \mathrm{~K}$ relative to the CTL 
Fig. 1 Vertical profile of sulfate aerosols used in our simulations, a the background aerosols in the CTL and $2 \mathrm{XCO} 2$ cases, b the ARCTIC case: $11 \mathrm{Mt}$ of sulfate aerosols prescribed from $50^{\circ} \mathrm{N}$ to $90^{\circ} \mathrm{N}, \mathrm{c}$ the POLAR case: $10 \mathrm{Mt}$ of sulfate aerosols prescribed from $50^{\circ} \mathrm{N}$ to $90^{\circ} \mathrm{N}$ and $8 \mathrm{Mt}$ of sulfate aerosols from $50^{\circ} \mathrm{S}$ to $90^{\circ} \mathrm{S}$, d the GLOBAL case: $20 \mathrm{Mt}$ of sulfate aerosols prescribed uniformly around the globe. Aerosols are prescribed from $78 \mathrm{hPa}$ to $9.8 \mathrm{hPa}$ in all the three geoengineering simulations with maximum concentration at $30 \mathrm{hPa}(\sim 22 \mathrm{~km})$. The dotted lines in the panels represent the tropopause in the respective simulations and the tropopause in the $2 \mathrm{XCO} 2$ case is shown by white solid line in a

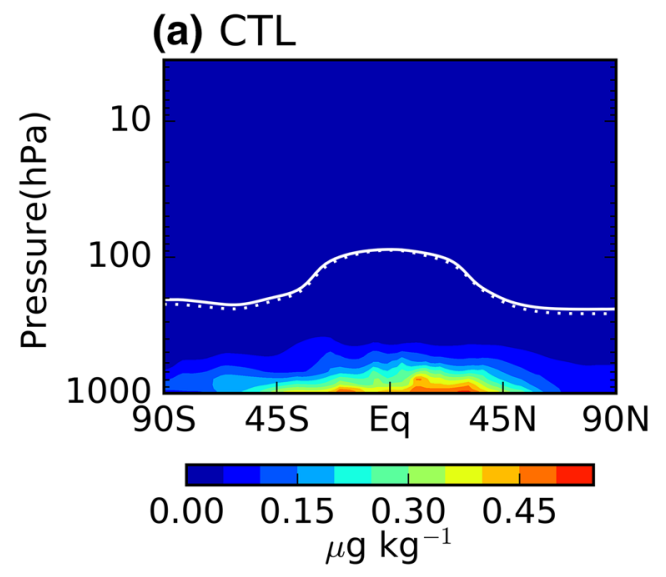

(b) ARCTIC

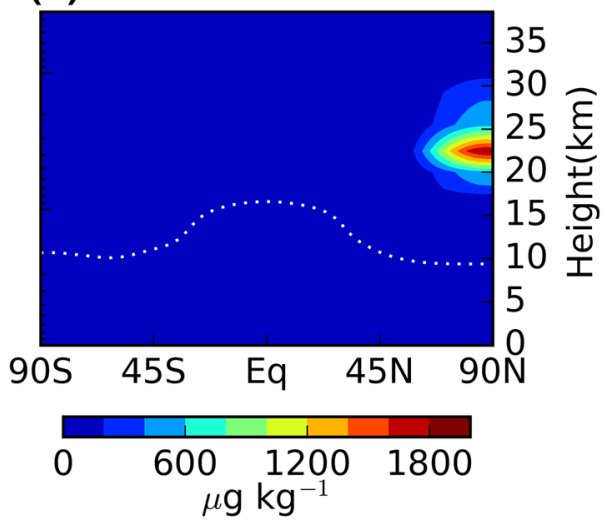

(c) POLAR

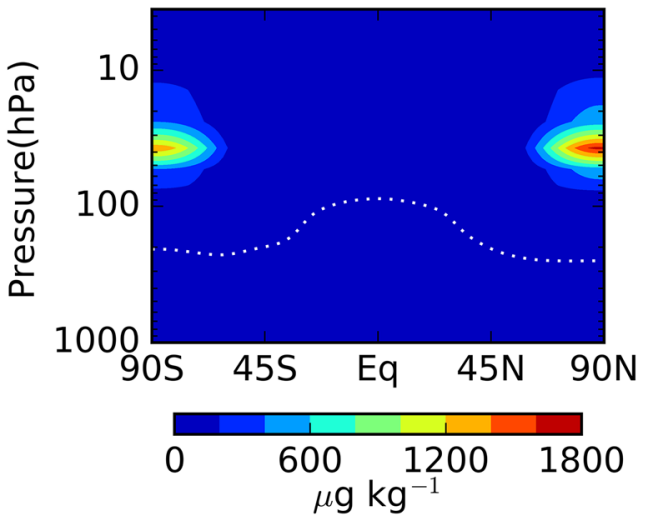

(d) GLOBAL

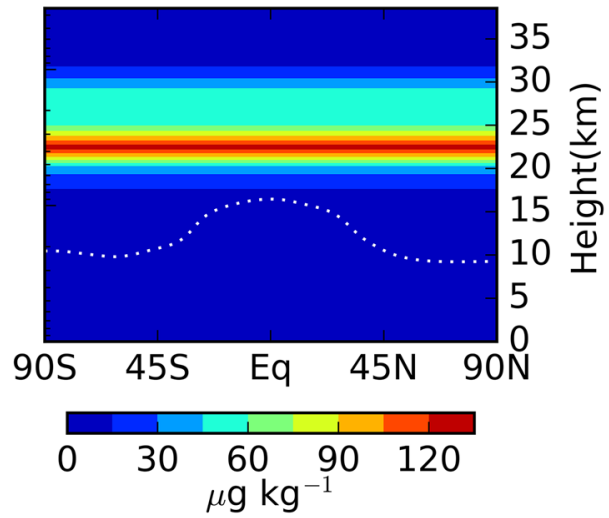

case and would not satisfy our design constraint. The Aerosol Optical Depth (AOD) and planetary albedo changes due to the geoengineering simulations are shown in Online Resource 1 (Figures S1, S2), and the radiative forcings are shown in Fig. 2.

In order to investigate the differences between the effects of Arctic geoenginering during the entire year vs the sunlit months of the year, we performed two additional experiments (Table 1): (1) ARCTIC_S: similar to ARCTIC but with $11 \mathrm{Mt}$ of sulfate aerosols prescribed in Arctic stratosphere only in the 6 sunlit months of the year from April to September; and (2) POLAR_S: similar to POLAR but with $10 \mathrm{Mt}$ of sulfate aerosols prescribed in Arctic stratosphere from April to September and $8 \mathrm{Mt}$ of sulfate aerosols prescribed in Antarctic stratosphere from October to March. Results of these experiments are discussed in Sect. 3.6.

The above set of simulations are performed in two different configurations: (1) Slab Ocean simulations that last for 100 years (of which the final 60 years were considered for analysis) are used to study climate change, and (2) prescribed-SST (sea surface temperature) simulations that last for 60 years (of which the final 30 years are used for analysis) are used to estimate the radiative forcing (Hansen et al. 1997). In the Prescribed-SST simulations the climatological monthly mean SST and sea ice concentration are prescribed.

\section{Results}

\subsection{Residual global climate change}

Unless specified, we discuss the annual mean responses of our simulations relative to the CTL case. Doubling of $\mathrm{CO}_{2}(2 \mathrm{XCO} 2)$ causes a top-of-atmosphere (TOA) radiative forcing of $3.5 \mathrm{Wm}^{-2}$, which is nearly uniform across all latitudes (Fig. 2a; Table 2). The ARCTIC case has a large negative forcing of $\sim-9 \mathrm{Wm}^{-2}$ relative to the CTL case, induced by the prescribed sulfate aerosol burden in the Arctic region, resulting in a smaller global mean radiative forcing $\left(2.22 \mathrm{Wm}^{-2}\right.$, Fig. $2 \mathrm{~b}$; Table 2$)$ compared to the $2 \mathrm{XCO} 2$ case. Similarly, the POLAR case shows relatively smaller global mean radiative forcing $\left(1.87 \mathrm{Wm}^{-2}\right)$ again because of the large negative forcing of -9 and $-3 \mathrm{Wm}^{-2}$ in the Arctic and Antarctic regions respectively (Fig. 2c; Table 2). The global mean radiative forcing in the GLOBAL case is 
(a) $2 \times C 02-\mathrm{CTL} \quad$ mean $=3.56 \mathrm{~W} \mathrm{~m}^{-2}$

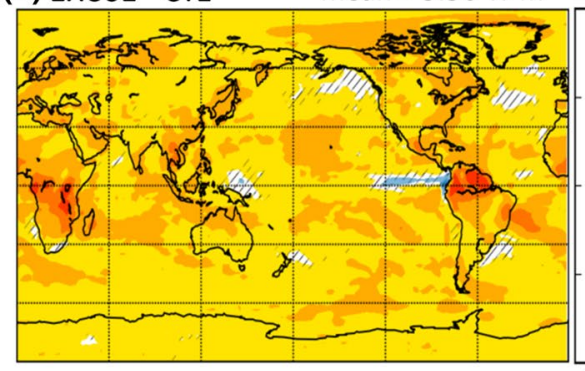

(c) POLAR - CTL mean $=1.88 \mathrm{~W} \mathrm{~m}^{-2}$

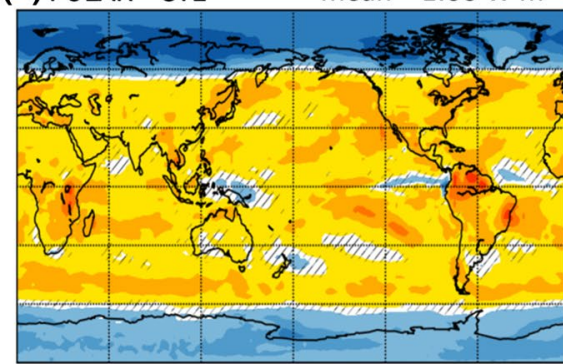

(b) ARCTIC - CTL

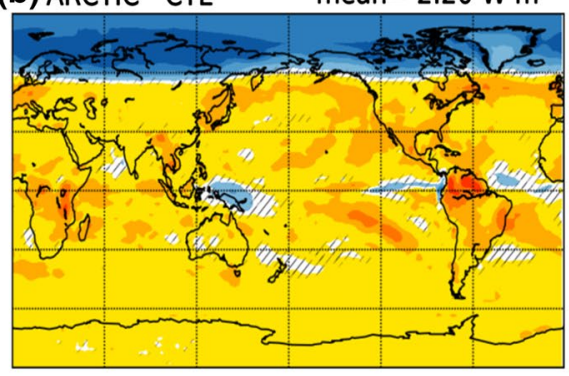

mean $=2.20 \mathrm{~W} \mathrm{~m}^{-2}$

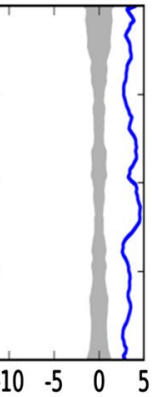

(d) GLOBAL - CTL
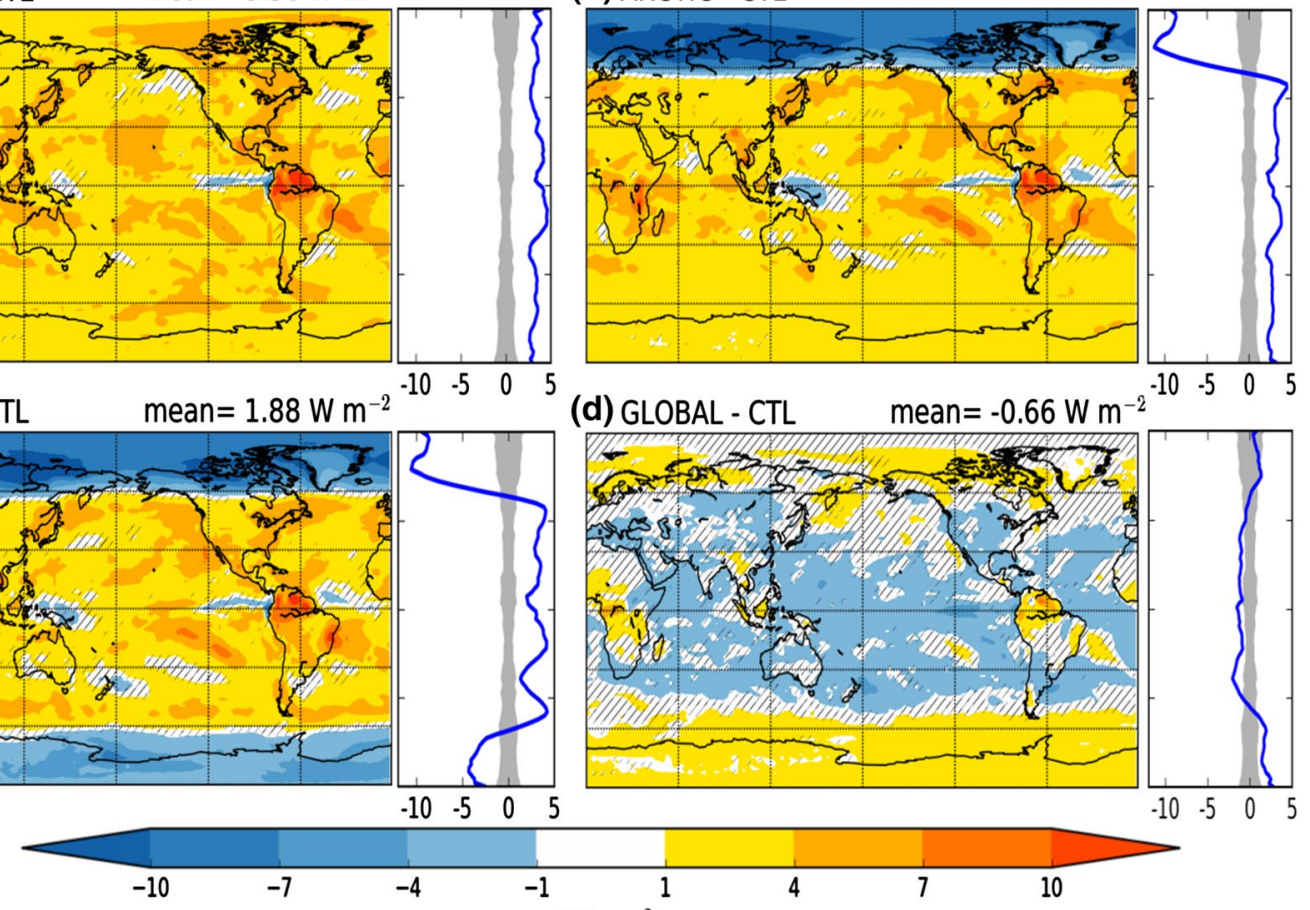

$\left(\mathrm{W} \mathrm{m}^{-2}\right)$

Fig. 2 Top-of-atmosphere radiative forcing [net radiative flux change at top of the atmosphere (TOA); $\left.\mathrm{Wm}^{-2}\right]$ estimated from the prescribed-SST simulations in the a $2 \mathrm{XCO} 2$, b ARCTIC, $\mathbf{c}$ POLAR and d GLOBAL cases relative to the CTL case. Hatched regions are not significant at the 5\% significance level estimated using student's $t$ test for 30 annual means and standard error corrected for autocorrelation (Zweirs and von Storch 1995). The zonal means are shown on the right of each panel and the width of the shading is equal to twice the standard deviation calculated from 30 annual means of the CTL case

by continental ice that already has a large albedo and prescribing aerosols over ice results in a small forcing. An effective approach for Antarctic forcing would be to introduce more solar reduction/sulfate loading near the latitudes where there is sea-ice (to reverse the positive ice-albedo feedback). This could ensure that more negative radiative forcing is induced in the Antarctic region for less sulfate loading (MacCracken et al. 2013). Such a forcing over Antarctic sea-ice requires tuning of the sulfate aerosols' latitudinal profile and can be achieved realistically through a
Table 2 Regional and global annual mean radiative forcing [net flux change at top of the atmosphere (TOA) relative to the CTL case]

\begin{tabular}{lcccr}
\hline Radiative forcing $\left(\mathrm{W} \mathrm{m}^{-2}\right)$ & $\begin{array}{l}\text { Arctic region } \\
\left(60^{\circ} \mathrm{N}-90^{\circ} \mathrm{N}\right)\end{array}$ & $\begin{array}{l}\text { Antarctic region } \\
\left(60^{\circ} \mathrm{S}-90^{\circ} \mathrm{S}\right)\end{array}$ & $\begin{array}{l}\text { Tropical region } \\
\left(30^{\circ} \mathrm{S}-30^{\circ} \mathrm{N}\right)\end{array}$ & Global mean \\
\hline 2XCO2-CTL & $3.54 \pm 0.22$ & $3.04 \pm 0.28$ & $3.98 \pm 0.11$ & $3.58 \pm 0.06$ \\
ARCTIC-CTL & $-8.83 \pm 0.23$ & $2.62 \pm 0.22$ & $3.04 \pm 0.12$ & $2.16 \pm 0.07$ \\
ARCTIC_S-CTL & $-7.77 \pm 0.21$ & $3.52 \pm 0.21$ & $3.90 \pm 0.12$ & $2.88 \pm 0.08$ \\
POLAR-CTL & $-8.15 \pm 0.28$ & $-2.78 \pm 0.18$ & $3.19 \pm 0.08$ & $1.89 \pm 0.05$ \\
POLAR_S-CTL & $-7.28 \pm 0.20$ & $-1.90 \pm 0.29$ & $3.99 \pm 0.09$ & $2.57 \pm 0.07$ \\
GLOBAL-CTL & $0.74 \pm 0.84$ & $1.73 \pm 0.71$ & $-1.19 \pm 0.31$ & $-0.67 \pm 0.20$ \\
\hline
\end{tabular}

Uncertainties are estimated as the standard errors calculated from 30 annual mean differences in net TOA fluxes 
tropospheric approach rather than a stratospheric approach, as the lifetime of tropospheric sulfate is much smaller than those in the stratosphere (MacCracken 2016).

The global mean surface warms by $3.1 \mathrm{~K}$ for a $\mathrm{CO}_{2}$ doubling (Fig. 3a; Table 3) and we estimate the climate sensitivity as $\sim 0.86 \mathrm{~K} / \mathrm{Wm}^{-2}$. In agreement with several previous studies (Govindasamy and Caldeira 2000; Govindasamy et al. 2003; Kravitz et al. 2016), we find that the polar regions warm much more than the global mean: the Arctic region $\left(60^{\circ} \mathrm{N}-90^{\circ} \mathrm{N}\right)$ warms by $\sim 6.5 \mathrm{~K}$ while the
Antarctic region $\left(60^{\circ} \mathrm{S}-90^{\circ} \mathrm{S}\right)$ warms by $\sim 5.5 \mathrm{~K}$ (Fig. 3a; Table 3). This enhanced warming at the poles is known as polar amplification and is mainly associated with the positive sea-ice albedo, temperature and water vapor feedbacks (Collins et al. 2013; Holland and Bitz 2003; Pithan and Mauritsen 2014).

In the ARCTIC case, the enhanced Arctic warming is nearly offset but the tropical and global means have residual warming of 1.5 and $2 \mathrm{~K}$, respectively (Fig. 3c; Table 3). In the POLAR case, both Arctic and Antarctic warming (a) $2 \times \mathrm{XO} 2-\mathrm{CTL}$

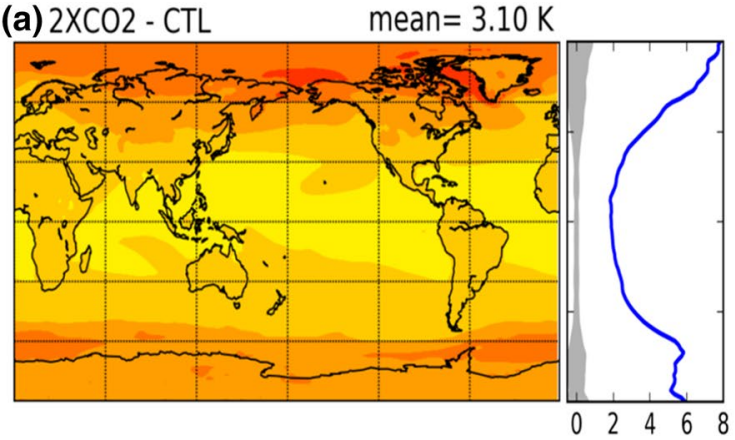

(c) POLAR - CTL

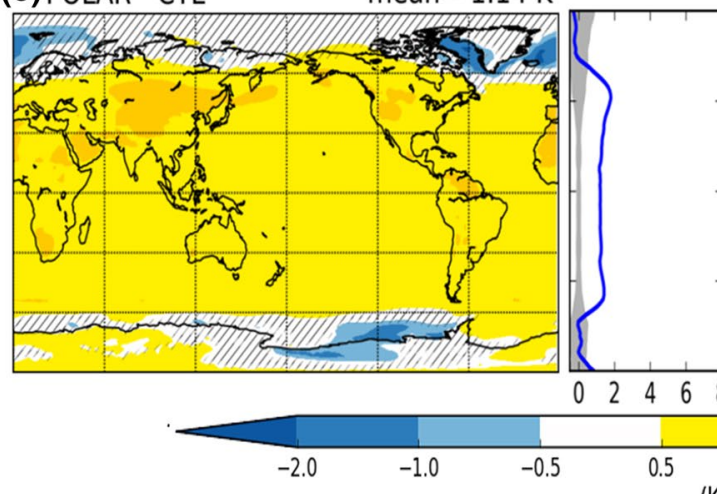

(b) ARCTIC - CTL
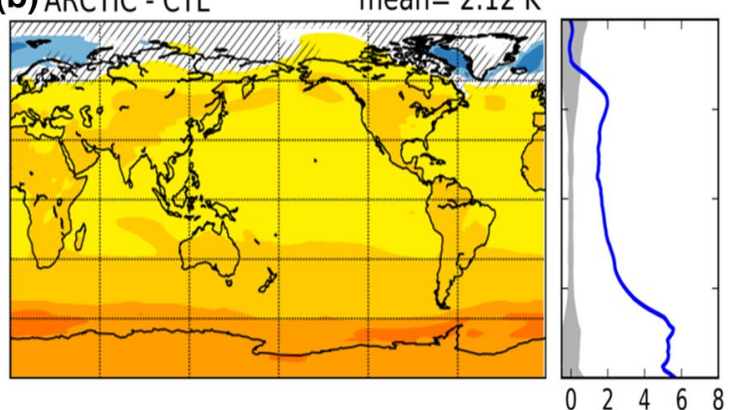

(d) GLOBAL - CTL

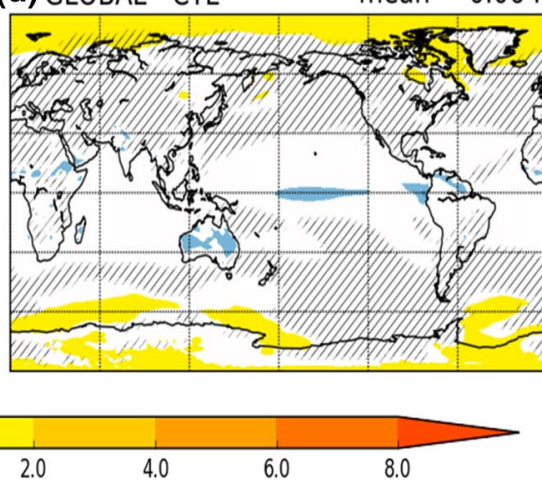

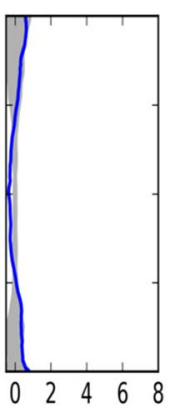

Fig. 3 Annual mean surface temperature anomalies $(\mathrm{K})$ in the a 2XCO2, b ARCTIC, $\mathbf{c}$ POLAR and $\mathbf{d}$ GLOBAL cases relative to the CTL case. Hatched regions are not significant at the 5\% significance level estimated using student's t test for 60 annual means and standard error corrected for autocorrelation (Zweirs and von Storch 1995). The zonal means are shown on the right of each panel and the width of the shading is equal to twice the standard deviation calculated from 60 annual means of the CTL case
Table 3 Regional and global annual mean surface temperatures $(\mathrm{K})$ for the CTL case and anomalies in the $2 \mathrm{XCO} 2$ and the geoengineering simulations relative to the CTL case

\begin{tabular}{lrcrr}
\hline Surface temperature $(\mathrm{K})$ & $\begin{array}{r}\text { Arctic region } \\
\left(60^{\circ} \mathrm{N}-90^{\circ} \mathrm{N}\right)\end{array}$ & $\begin{array}{l}\text { Antarctic region } \\
\left(60^{\circ} \mathrm{S}-90^{\circ} \mathrm{S}\right)\end{array}$ & $\begin{array}{l}\text { Tropical region } \\
\left(30^{\circ} \mathrm{S}-30^{\circ} \mathrm{N}\right)\end{array}$ & \multicolumn{1}{c}{ Global mean } \\
\hline CTL & $259.02 \pm 0.46$ & $250.70 \pm 0.38$ & $298.41 \pm 0.08$ & $287.19 \pm 0.18$ \\
2XCO2-CTL & $6.63 \pm 0.09$ & $5.51 \pm 0.08$ & $2.07 \pm 0.02$ & $3.10 \pm 0.02$ \\
ARCTIC-CTL & $0.24 \pm 0.08$ & $5.33 \pm 0.06$ & $1.73 \pm 0.02$ & $2.12 \pm 0.02$ \\
ARCTIC_S-CTL & $0.73 \pm 0.10$ & $5.24 \pm 0.07$ & $1.77 \pm 0.02$ & $2.22 \pm 0.02$ \\
POLAR-CTL & $0.01 \pm 0.10$ & $0.13 \pm 0.07$ & $1.23 \pm 0.02$ & $1.14 \pm 0.02$ \\
POLAR_S-CTL & $0.45 \pm 0.08$ & $0.91 \pm 0.06$ & $1.37 \pm 0.02$ & $1.40 \pm 0.02$ \\
GLOBAL-CTL & $0.39 \pm 0.20$ & $0.37 \pm 0.15$ & $-0.26 \pm 0.02$ & $-0.06 \pm 0.03$ \\
\hline
\end{tabular}

Uncertainties are estimated as the standard errors calculated from 60 annual mean differences. However, for the CTL case, uncertainty is estimated as the standard deviation from 60 annual means 
is nearly offset but the tropical and global regions still have a residual warming of about $1 \mathrm{~K}$ (Fig. 3c; Table 3 ). In the POLAR case, we have prescribed a smaller amount of sulfate aerosols in the Antarctic than the Arctic, as the warming in the Antarctic due to $\mathrm{CO}_{2}$ doubling $(5.5 \mathrm{~K})$ is less than that of the Arctic region (6.5 K) (Table 3). In the GLOBAL case, the global average temperature is restored with slight residual warming over the Arctic and Antarctic regions and residual cooling over the tropics (Table 2) in agreement with global scale geoengineering studies in the past (Govindasamy et al. 2003; Kravitz et al. 2016).

In the $2 \mathrm{XCO} 2$ case, we simulate a decline in annual mean sea-ice extent of $\sim 3.5$ million $\mathrm{km}^{2}(\sim 26 \%)$ in the Arctic and $\sim 6$ million $\mathrm{km}^{2}(\sim 42 \%)$ in the Antarctic (Table 4). We simulate more percentage reduction in sea-ice extent in the end of summer (September in the Arctic and February in the Antarctic) than the annual mean due to strong positive ice-albedo mechanism during summertime. The reduction in sea-ice in the Arctic region during September in the $2 \mathrm{XCO} 2$ case is $\sim 47 \%$, whereas observations show that the September sea-ice extent in the Arctic shrunk by $~ 55 \%$ from 1980 to 2012 although $\mathrm{CO}_{2}$ has not doubled relative to the pre-industrial levels (Jeffries et al. 2013). This shows that our model underestimates the Arctic sea-ice extent decline. In the ARCTIC case, the sea-ice extent of Arctic region is restored to the pre-industrial level but we find that the Antarctic sea-ice still has a decline of $\sim 6$ million $\mathrm{km}^{2}$ because of the residual warming in the Antarctic. In the POLAR case, we find that the annual mean sea-ice extent in both polar regions is restored (Table 4). In the GLOBAL case, we simulate a near restoration of both Arctic and Antarctic sea-ice extent (Table 4), despite a slight residual warming in the polar regions as discussed previously (Table 3).

We simulate a $\sim 5 \%$ increase in global mean precipitation in the $2 \mathrm{XCO} 2$ case and find that the hydrological sensitivity is $\sim 1.8 \% \mathrm{~K}^{-1}$, in agreement with earlier studies which used a previous version of the same model (e.g. Bala et al. 2010).
Similar to past geoengineering modeling studies (e.g. Bala et al. 2008; Tilmes et al. 2013; Cao et al. 2016), we find that the global mean precipitation decreases by $\sim 2.5 \%$ in the GLOBAL case relative to the CTL case (Fig. 4d). This precipitation reduction in the GLOBAL case is because of the differences in the fast response of the climate system to solar and $\mathrm{CO}_{2}$ forcings (Bala et al. 2008, 2010; Cao et al. 2012). However, we find that the global mean precipitation increases by $\sim 4$ and $~ 2 \%$ in the ARCTIC and POLAR cases respectively relative to the CTL case, because of the residual global mean warming (Table 3). This increase in global mean precipitation in the ARCTIC and POLAR cases can also be related to the geoengineering location: the regions where most evaporation occurs (tropics and mid-latitudes) are not the locations where additional aerosols are prescribed (Caldeira and Wood 2008; MacCracken et al. 2013).

Figure 4 shows that in the ARCTIC case, the zonal mean precipitation in the tropics decreases (increases) significantly in the $\mathrm{NH}(\mathrm{SH})$ by $\sim 0.5 \mathrm{~mm} \mathrm{day}^{-1}$ associated with a southward shift of the ITCZ relative to the CTL case (Fig. 4b). However, in the POLAR case, we simulate much smaller zonal mean precipitation anomalies in the tropics relative to the CTL case, as there is little southward shift in ITCZ (Fig. 4c). These results are in agreement with MacCracken et al. (2013) where Arctic geoengineering is simulated by reducing the solar constant. In the next section, we present a detailed analysis of ITCZ shifts and precipitation response in the global monsoon regions due to the geoengineering simulations. We recognise that changes in precipitation minus evapotranspiration $(\mathrm{P}-\mathrm{E})$ are ecologically more important than the changes in precipitation alone and hence we discuss the spatial pattern of changes in evapo-transpiration and $\mathrm{P}-\mathrm{E}$ for the 2XCO2, ARCTIC, POLAR and GLOBAL cases relative to the CTL case in Figures S3 and S4 (Online Resource 1) respectively.

Table 4 Sea ice extent in the CTL case and the changes in the $2 \mathrm{XCO} 2$ case and geoengineering simulations relative to the CTL case

\begin{tabular}{|c|c|c|c|c|}
\hline \multirow{2}{*}{$\begin{array}{l}\text { Mean sea ice extent } \\
\left(10^{6} \mathrm{~km}^{2}\right)\end{array}$} & \multicolumn{2}{|l|}{ Arctic sea ice extent } & \multicolumn{2}{|l|}{ Antarctic sea ice extent } \\
\hline & Annual & September & Annual & February \\
\hline CTL & $13.42 \pm 0.23$ & $9.62 \pm 0.24$ & $14.64 \pm 0.61$ & $6.01 \pm 0.62$ \\
\hline 2XCO2-CTL & $-3.49 \pm 0.04(-26.00 \%)$ & $-4.55 \pm 0.07(-47.30 \%)$ & $-6.07 \pm 0.10(-41.36 \%)$ & $-3.49 \pm 0.10(-57.54 \%)$ \\
\hline ARCTIC-CTL & $-0.12 \pm 0.04(-0.83 \%)$ & $0.86 \pm 0.05(9.03 \%)$ & $-5.90 \pm 0.08(-40.19 \%)$ & $-3.50 \pm 0.09(-57.78 \%)$ \\
\hline ARCTIC_S-CTL & $-0.35 \pm 0.04(-2.58 \%)$ & $0.67 \pm 0.05(7.07 \%)$ & $-5.84 \pm 0.08(-39.82 \%)$ & $-3.42 \pm 0.08(-56.67 \%)$ \\
\hline POLAR-CTL & $-0.03 \pm 0.05(-0.16 \%)$ & $0.80 \pm 0.05(8.45 \%)$ & $-0.24 \pm 0.09(-1.50 \%)$ & $1.79 \pm 0.11(31.07 \%)$ \\
\hline POLAR_S-CTL & $-0.31 \pm 0.03(-2.31 \%)$ & $0.61 \pm 0.04(6.40 \%)$ & $-1.28 \pm 0.08(-8.59 \%)$ & $0.98 \pm 0.10(17.41 \%)$ \\
\hline GLOBAL-CTL & $-0.22 \pm 0.04(-1.61 \%)$ & $-0.20 \pm 0.04(-2.06 \%)$ & $-0.51 \pm 0.10(-3.30 \%)$ & $-0.10 \pm 0.10(-0.84 \%)$ \\
\hline
\end{tabular}

Uncertainties are estimated as the standard errors from 60 annual/monthly mean differences. However, for the CTL case, uncertainty is estimated as the standard deviation from 60 annual/monthly means. Values in parentheses show percentage changes relative to the CTL case 
(a) $2 \times \mathrm{CO}$ - CTL

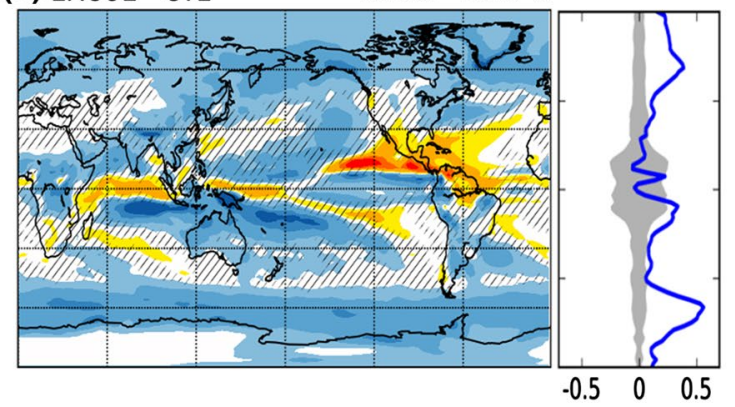

(c) POLAR - CTL

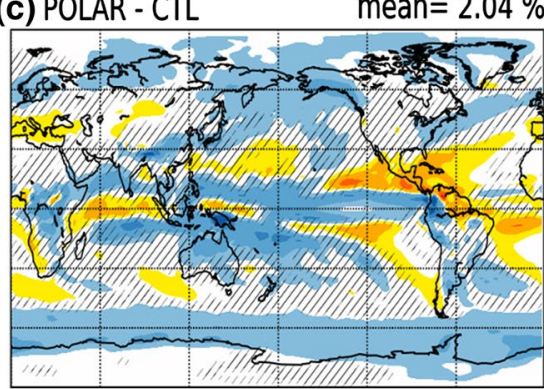

(b) ARCTIC - CTL

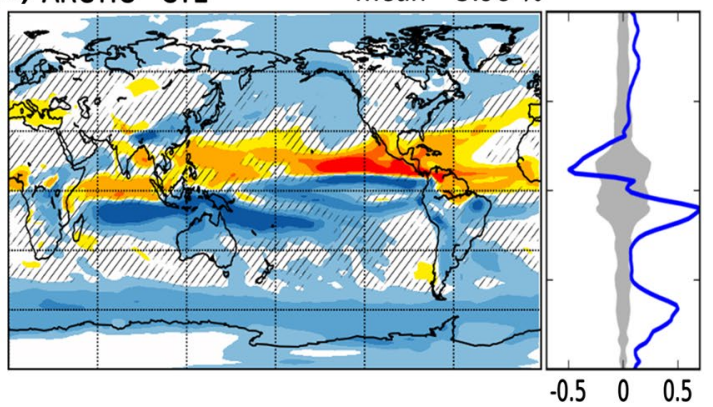

(d) GLOBAL - CTL

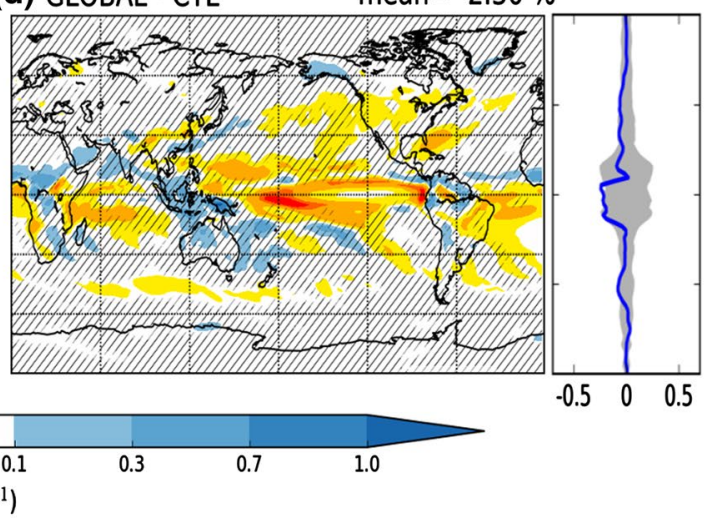

Fig. 4 Annual mean precipitation anomalies $\left(\mathrm{mm} \mathrm{day}^{-1}\right)$ in the a 2XCO2, b ARCTIC, $\mathbf{c}$ POLAR and $\mathbf{d}$ GLOBAL cases relative to the CTL case. Hatched regions are not significant at the 5\% significance level estimated using student's t test for 60 annual means and standard

There are also differences between the geoengineering simulations in the partition between direct and diffuse radiation, which could alter carbon uptake by plants. Geoengineering increases the amount of diffuse radiation reaching the surface, but decreases the direct radiation as found in previous studies (Xia et al. 2016; Kalidindi et al. 2014). This effect on global mean direct and diffuse radiations is more prominent in the GLOBAL case than in the ARCTIC and POLAR cases (Online Resource 1: Table S1). The changes in diffuse radiation fraction in the Arctic could be as big as $16 \%$ for the ARCTIC case during the summer months. However, this change in the diffuse radiation in the Arctic would not have substantial effect on the primary productivity over land as there is little vegetation in the Arctic (Online Resource 1: Table S2).

Arctic geoengineering has potential to build snow in the Arctic region and moderate the loss of ice from Greenland ice sheet and the rate of sea-level rise (Caldeira and Wood 2008). Online Resource 1: Figure S5 shows that there is more snow accumulation in the Arctic region for both ARCTIC and POLAR cases, relative to the CTL case, mainly during the summertime. In the GLOBAL case, however, we simulate only a small increase in snowfall. The increase in snowfall in the ARCTIC and POLAR cases error corrected for autocorrelation (Zweirs and von Storch 1995). The zonal means are shown on the right of each panel and the width of the shading is equal to twice the standard deviation in the CTL case

relative to the CTL case is likely due to the residual warming outside of the geoengineering domain and the consequent increase in poleward transport of water vapor.

\subsection{Precipitation changes in monsoon regions and shift in ITCZ}

In order to investigate the effect of geoengineering on tropical precipitation, we study the monsoon regions which are selected based on the criteria developed by Wang and Ding (2006). Annual range is defined as the difference between the local summer [June-July-August (JJA) for $\mathrm{NH}$; December-January-February (DJF) for SH] and the local winter precipitation (DJF for NH; JJA for SH). The tropical areas where the annual range exceeds $180 \mathrm{~mm}$, and the local summer precipitation contributes to more than $35 \%$ of annual precipitation would qualify for consideration under monsoon precipitation domain. We plot this monsoon precipitation domain from the CTL case and demarcate the areas of interest in order to establish seven monsoon regions (Online Resource 1: Figure S6; Table S3). These monsoon regions constitute four regions in the $\mathrm{NH}$ : East Asia (EA), North America (NA), North Africa (NAf) 
and South Asia (SAs), and 3 regions in SH: South America (SA), South Africa (SAf) and Australia (AUS).

When changes relative to the CTL case are considered in the analysis of precipitation changes in the geoengineering experiments, there is a combined effect of both $\mathrm{CO}_{2}$ doubling and geoengineering. In order to exclusively estimate the effects of geoengineering we separate the geoengineering effects from the combined effect by analysing precipitation changes relative to the $2 \mathrm{XCO} 2$ case. Here, the changes due to geoengineering relative to the $2 \mathrm{XCO} 2$ case denote the exclusive effect of geoengineering whereas those relative to the CTL case denote the combined effect of $\mathrm{CO}_{2}$ doubling and geoengineering.

We also discuss the location of ITCZ and the shift in its position in our experiments. ITCZ position is located using a metric called precipitation centroid $\left(\mathrm{P}_{\text {cent }}\right)$ defined as the median latitude of zonal mean area-weighted precipitation between $20^{\circ} \mathrm{S}$ and $20^{\circ} \mathrm{N}$, interpolated to a $0.01^{\circ}$ grid as used in many previous studies (Devaraju et al. 2015; Donohoe et al. 2013; Frierson and Hwang 2012). The mechanisms leading to the shifting of ITCZ are discussed in the next subsection.

In the $2 \mathrm{XCO} 2$ case, we find an increased annual mean and summer precipitation in all monsoon regions except NA (Fig. 5). We simulate a decrease in precipitation for NA region which is in agreement with observed trends and previous modeling studies (Neelin et al. 2006; Christensen et al. 2013). It should be noted that a reasonable proportion of precipitation in the NA region comes from tropical cyclone events that global climate models do not simulate adequately (Christensen et al. 2007). The CTL case's $\mathrm{P}_{\text {cent }}$ is located in the southern hemisphere in our model indicating that the SH tropics receive slightly more rainfall than NH tropics. As analysed by Frierson and Hwang (2012), models showing $P_{\text {cent }}$ in the southern hemisphere in their control simulation tend to shift their $\mathrm{P}_{\text {cent }}$ southward for $\mathrm{CO}_{2}$ increase, as wet regions tend to get wetter for an increase in $\mathrm{CO}_{2}$ (Held and Soden 2006). This implies that the increase in the $\mathrm{SH}$ tropical rainfall in the $2 \mathrm{XCO} 2$ case is more than that in $\mathrm{NH}$, shifting the $\mathrm{P}_{\text {cent }}$ southward. The changes in run-off ratio in the $2 \mathrm{XCO} 2$ case are similar to changes in precipitation for the $\mathrm{NH}$ and $\mathrm{SH}$ monsoon regions (Online Resource 1: Figure S7).

The ARCTIC case shows a reduction in both seasonal and annual mean precipitation in all $\mathrm{NH}$ monsoon regions relative to the $2 \mathrm{XCO} 2$ case (Fig. 6a). We find up to $9 \%$ reduction in annual mean precipitation in NAf monsoon region. However, we find a smaller contribution to annual mean precipitation reduction from summers (JJA/JJAS). We find only up to $7 \%$ reduction during summers in SAs and $5 \%$ in EA monsoon regions. This reduction in precipitation when combined with increase in precipitation due to $\mathrm{CO}_{2}$ doubling (Fig. 5a) would cause a near restoration of
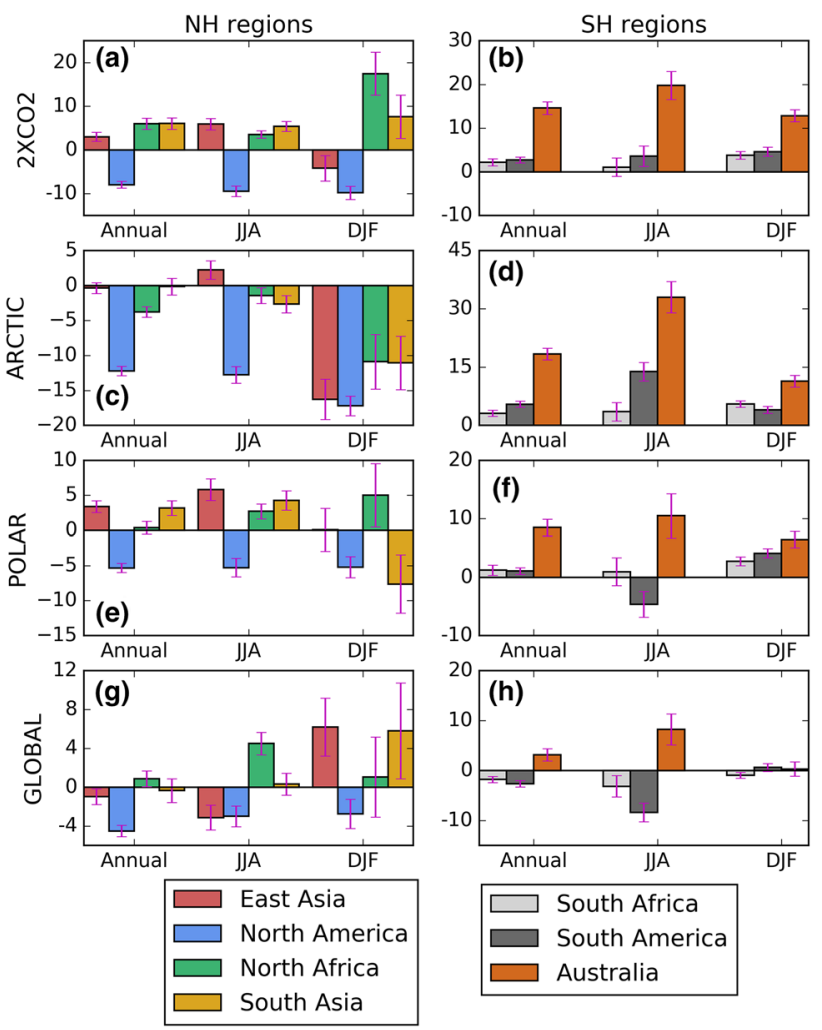

Fig. 5 Percentage changes in precipitation in the monsoon regions relative to the CTL case. Left (right) panels show changes in the $\mathrm{NH}$ (SH) monsoon regions. These changes signify the effects of both geoengineering (aerosol additions) and $\mathrm{CO}_{2}$ doubling in $\mathbf{a}$, b ARCTIC, c, d POLAR, e , f GLOBAL simulations. Changes are shown for annual, JJA (JJAS for South Asia) and DJF means. Uncertainty (error bars) is estimated as the standard error from 60 annual or seasonal mean changes. Note the variation in scales between the panels

annual and summer precipitation in EA and SAs monsoon regions (Fig. 5c; precipitation changes relative to the CTL case). In NA monsoon region, however, we find a decrease in precipitation due to the $2 \mathrm{XCO} 2$ case which is enhanced in the ARCTIC case (Figs. 2a, 5a) during summer and winter seasons and in the annual mean. There is a net annual and summer mean precipitation decrease in EA monsoon region as the increase in precipitation due to $\mathrm{CO}_{2}$ doubling is smaller when compared to the decrease in precipitation due to Arctic geoengineering. Overall, there is a reduced annual mean and summer precipitation in the ARCTIC case relative to the CTL case for most $\mathrm{NH}$ monsoon regions (Fig. 5c).

In contrast, there is a slightly increased annual mean precipitation of up to 5\% in the $\mathrm{SH}$ regions (Fig. 6b) in the ARCTIC case relative to the $2 \mathrm{XCO} 2$ case. This increase in precipitation due to Arctic geoengineering is amplified by $\mathrm{CO}_{2}$ increase (Fig. $5 \mathrm{~b}$, d; precipitation changes relative to the CTL case), especially in the 

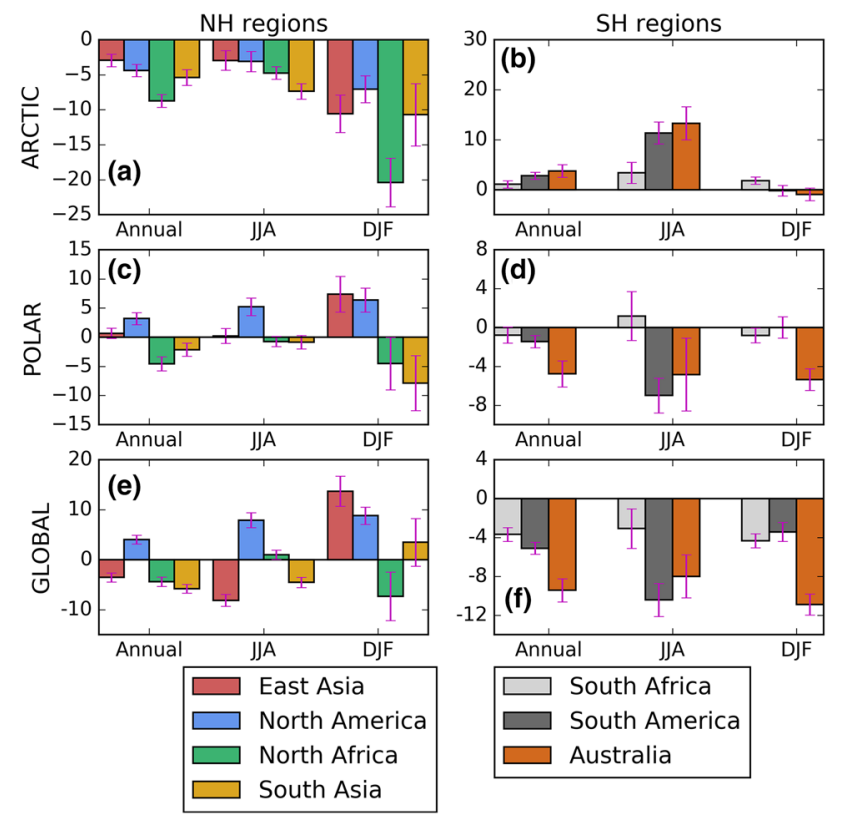

Fig. 6 Same as Fig. 5 but changes are relative to the $2 \mathrm{XCO} 2$ case (in $\%$ ). These changes signify the exclusive effect of geoengineering (aerosol additions). Note the variation in scales between the panels

Table 5 Annual mean northward atmospheric heat transport at the equator $\left(\mathrm{AHT}_{\mathrm{eq}}\right)$, ITCZ location $\left(\mathrm{P}_{\text {cent }}\right)$ and inter-hemispheric temperature gradient $\left(\Delta \mathrm{T}_{\mathrm{h}}\right)$ for different experiments

\begin{tabular}{lllr}
\hline & $\mathrm{AHT}_{\text {eq }}(\mathrm{PW})$ & $\mathrm{P}_{\text {cent }}($ degrees latitude $)$ & \multicolumn{1}{c}{$\Delta \mathrm{T}_{\mathrm{h}}(\mathrm{K})$} \\
\hline $\mathrm{CTL}$ & $0.05 \pm 0.07$ & $-0.64 \pm 0.54$ & $0.65 \pm 0.15$ \\
2 XCO2 & $0.14 \pm 0.07$ & $-1.07 \pm 0.38$ & $0.90 \pm 0.16$ \\
ARCTIC & $0.28 \pm 0.06$ & $-2.11 \pm 0.46$ & $-0.71 \pm 0.07$ \\
ARCTIC_S & $0.28 \pm 0.08$ & $-2.01 \pm 0.47$ & $-0.51 \pm 0.15$ \\
POLAR & $0.12 \pm 0.06$ & $-0.79 \pm 0.54$ & $0.75 \pm 0.16$ \\
POLAR_S & $0.12 \pm 0.08$ & $-0.80 \pm 0.48$ & $0.67 \pm 0.07$ \\
GLOBAL & $0.05 \pm 0.07$ & $-0.58 \pm 0.46$ & $0.67 \pm 0.15$ \\
\hline
\end{tabular}

The uncertainties are estimated as standard deviations from 60 annual means

SH winter and annual mean. In the SA monsoon region, however, the net increase in winter precipitation of $13 \%$, relative to the CTL case, is mainly contributed by geoengineering (addition of stratospheric aerosols on the Arctic; changes relative to the $2 \mathrm{XCO} 2$ case). Although the SH summer (DJF) precipitation is nearly not altered by geoengineering (Fig. 6d; precipitation changes relative to the $2 \mathrm{XCO} 2$ case), we see a net increase of up to $10 \%$ due to the combined effects of geoengineering and $\mathrm{CO}_{2}$ doubling (Fig. 5b, d; precipitation changes relative to the CTL case). Therefore, there is an increased precipitation relative to the CTL case in all seasons for all SH monsoon regions in the ARCTIC case (Fig. 5c). The changes in annual mean runoff ratio $[(\mathrm{P}-\mathrm{E}) / \mathrm{P}]$ are similar to precipitation changes in the ARCTIC case: there is a reduction (increase) in $\mathrm{NH}(\mathrm{SH})$ monsoon regions (Online Resource 1: Figure S7).

The POLAR case, relative to the $2 \mathrm{XCO} 2$ case, shows much smaller changes in precipitation in the monsoon regions compared to the ARCTIC case. Only small changes in precipitation of up to $\pm 5 \%$ are seen in the monsoon regions of both hemispheres (Fig. 6c, d). We find from Fig. $4 \mathrm{c}$, that the intensity of the anomalous precipitation bands in the tropical regions is small, in the POLAR case when compared to the ARCTIC case (Fig. 4b). As opposed to a $1.5^{\circ}$ southward shift of $\mathrm{P}_{\text {cent }}$ in the ARCTIC case, there is a shift of only $0.15^{\circ}$ in the POLAR case which is within the \pm 1 standard deviation of the CTL case $\left(0.5^{\circ}\right.$; Table 5$)$. This shows that the POLAR case nearly restores the ITCZ shift caused by Arctic geoengineering to that of the CTL case. We find that the annual mean and summer precipitation increases by up to $7 \%$ in all monsoon regions except NA in the POLAR case relative to the CTL case (Fig. 5e, f). This residual increase of $7 \%$, despite the restoration of ITCZ location, is due to the residual $\mathrm{CO}_{2}$ induced warming in the tropical regions in the POLAR case. The change in run-off ratio also shows a residual increase of up to $7 \%$ (Online Resource 1: Figure S7).

In the GLOBAL case, precipitation decreases in most regions of both hemispheres relative to the $2 \mathrm{XCO} 2$ case (the effect of geoengineering). Annual mean precipitation reduces up to $7 \%$ in $\mathrm{NH}$ monsoon regions and up to $10 \%$ in SH monsoon regions (Fig. 6e, f). In the NA region, however, there is an increase of up to $\sim 3 \%$. When the effects of $\mathrm{CO}_{2}$ doubling are included, we find a smaller reduction in annual mean precipitation in most regions (Fig. $5 \mathrm{~g}, \mathrm{~h}$ ). These precipitation reductions can be attributed to the overcooling of the tropics (Fig. 3d), as simulated by past modelling studies (Govindasamy et al. 2003; Kravitz et al. 2016). There is an increase in the run-off ratio (Online Resource 1: Figure S7) as P-E in the tropical regions increases (Online Resource 1: Figure S4) but these changes are mostly not significant. We see almost no shift in the ITCZ location in the GLOBAL case (Table 5) which is consistent with previous studies (Modak and Bala 2014). Since the $\mathrm{CO}_{2}$ induced warming and hence precipitation changes are nearly offset and the ITCZ does not shift,, we find that the overall precipitation changes are within $\pm \sim 2 \%$ in the GLOBAL case for most monsoon regions. However, it should be noted that the changes in regional precipitation are not consistent between different models (Kravitz et al. 2014).

\subsection{ITCZ shifts and atmospheric heat transport}

The changes in cross-equatorial atmospheric heat transport have been investigated in many previous studies which relate the shifts in ITCZ due to various phenomena and 
forcings to changes in heat transports (Frierson and Hwang 2012; Donohoe et al. 2013; Devaraju et al. 2015). The annual mean northward heat transport (AHT) is calculated under steady state assumptions as:

$A H T(\phi)=\int_{90^{\circ} S}^{\phi}\left(Q_{T O A}-Q_{s}\right) a^{2} \cos \phi d \phi$,

$Q_{T O A}=F_{S W, T O A}-F_{L W, T O A}$,

$Q_{S}=F_{S W, S F C}-F_{L W, S F C}-S H-L H$,

where $a$ is the radius of the Earth, $\mathrm{Q}_{\mathrm{TOA}}$ is the top-ofatmosphere (TOA) energy budget with $\mathrm{F}_{\text {SW,TOA }}$ and $\mathrm{F}_{\text {LW,TOA }}$ being the TOA shortwave and longwave zonal mean fluxes respectively, $Q_{S}$ is the surface energy budget with $\mathrm{F}_{\mathrm{SW}, \mathrm{SFC}}$ and $\mathrm{F}_{\mathrm{LW}, \mathrm{SFC}}$ being the shortwave and longwave zonal mean fluxes at surface at a given latitude $\phi$, and $\mathrm{SH}$ and LH are the zonal mean sensible heat and latent heat fluxes at a given latitude $\phi$. We find that the cooling in the Arctic region in the ARCTIC and POLAR cases leads to an increased northward $\mathrm{AHT}$ at the equator $\left(\mathrm{AHT}_{\mathrm{eq}}\right)$ relative to the CTL case, with heat transport anomalies reaching maximum values of $0.4 \mathrm{PW}$ near $60^{\circ} \mathrm{N}$. Similarly, the maximum in southward AHT anomaly is simulated in the POLAR case at $60^{\circ} \mathrm{S}$ (Fig. 7). However, in the GLOBAL case, the AHT anomalies are within the \pm 1 standard deviation of the CTL case (Fig. 7; Table 5), keeping the $\mathrm{AHT}_{\text {eq }}$ change insignificant. It is likely that the increased poleward heat transport in the ARCTIC and POLAR cases in the mid- to high-latitudes is mainly due to poleward latent heat flux due to the residual warming in the non-polar regions (Tilmes et al. 2014). This can explain why there is little change in the GLOBAL case. The enhanced latent heat transport in the ARCTIC and POLAR cases leads to more snowfall in the Arctic region (Online Resource 1: Figure S5).

We notice from Table 5 that a larger $\mathrm{AHT}_{\text {eq }}$ would correspond to a more southward location of $\mathrm{P}_{\text {cent }}$. Since the $\mathrm{AHT}_{\text {eq }}$ changes are driven by changes in the temperature gradient between the hemispheres, (Donohoe et al. 2013; McGee et al. 2013), we also analyse the hemispherical temperature gradient $\left(\Delta \mathrm{T}_{\mathrm{h}}\right)$, defined as the difference between the northern and southern hemisphere's mean surface temperature.

A cooler northern hemisphere (or smaller $\Delta \mathrm{T}_{\mathrm{h}}$ ) would imply a tendency for more heat to be transported from the southern hemisphere to the northern hemisphere, in turn leading to a larger $\mathrm{AHT}_{\mathrm{eq}}$. As discussed previously, larger $\mathrm{AHT}_{\text {eq }}$ corresponds to more southward location of $\mathrm{P}_{\text {cent }}$. In order to verify this, we perform 100 -year simulations with prescribed sulfate aerosol burdens in the Arctic ranging from 4 to $16 \mathrm{Mt}$ in increments of $4 \mathrm{Mt}$, and analyse

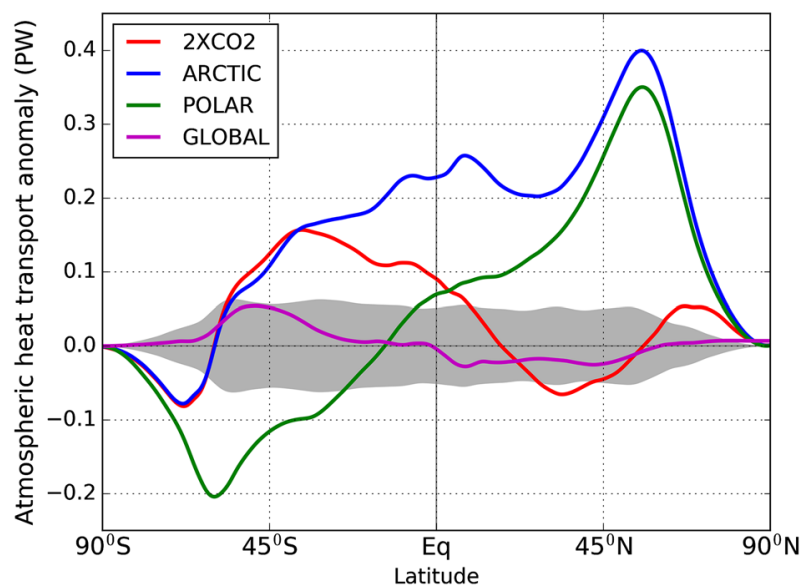

Fig. 7 Latitudinal profile of annual mean northward atmospheric heat transport anomalies relative to the CTL case for the $2 \mathrm{XCO} 2$, ARCTIC, POLAR and GLOBAL cases. Height of the shading is equal to twice the standard deviation calculated from 60 annual means of the CTL case

variation in the location of $\mathrm{P}_{\text {cent }}$ in the last 60 years. The sulfate aerosol prescription profile and region of prescription and $\mathrm{CO}_{2}$ levels are similar to the ARCTIC case as discussed in Sect. 2.2 and Table 1. From Fig. 8, we find a strong linear relationship between $\mathrm{AHT}_{\mathrm{eq}}$ and $\Delta \mathrm{T}_{\mathrm{h}}$ $\left(\mathrm{R}^{2}=0.99\right.$; Fig. 8a) and also between and $\mathrm{P}_{\text {cent }}$ and $\Delta \mathrm{T}_{\mathrm{h}}$ $\left(\mathrm{R}^{2}=0.98\right.$; Fig. $\left.8 \mathrm{~b}\right)$. This confirms our previous finding that $\mathrm{P}_{\text {cent }}$ shifts southward for a cooler northern hemisphere and larger $\mathrm{AHT}_{\mathrm{eq}}$. Hence, we conclude that a larger sulfate aerosol burden in the Arctic cools the $\mathrm{NH}$ increasing the $\Delta \mathrm{T}_{\mathrm{h}}$. This larger $\Delta \mathrm{T}_{\mathrm{h}}$ drives more heat from $\mathrm{SH}$ to the $\mathrm{NH}$ thereby increasing the $\mathrm{AHT}_{\text {eq }}$. This increased $\mathrm{AHT}_{\mathrm{eq}}$ is associated with a more southward location of $\mathrm{P}_{\text {cent }}$. We also find that successive increases in sulfate burden in the Arctic causes smaller southward shifts in $\mathrm{P}_{\text {cent }}$. This is because the planetary albedo in the Arctic region tends to saturate for successive sulfate aerosol additions (Fig. 8c).

The ITCZ is the location where the convergence of upwelling limbs of the Hadley circulation occurs. The Hadley cell is a thermally direct circulation that transports heat poleward. Most of the poleward heat transport by the Hadley cell is contributed by its upper poleward limb (Donohoe et al. 2013). Since the NH is cooled in the ARCTIC case, the NH Hadley circulation shifts in such a way that more heat is transported from the warmer $\mathrm{SH}$ to the cooler $\mathrm{NH}$. More cross-equatorial northward atmospheric heat transport $\left(\mathrm{AHT}_{\mathrm{eq}}\right)$ implies that the NH Hadley cell tends to shift southward, hence, the ITCZ also shifts southward (Donohoe et al. 2013). Thus, we find a teleconnection between Arctic cooling by geoengineering and changes in tropical precipitation patterns.

Similar to past studies (Donohoe et al. 2013; McGee et al. 2013; Devaraju et al. 2015) we investigate the 

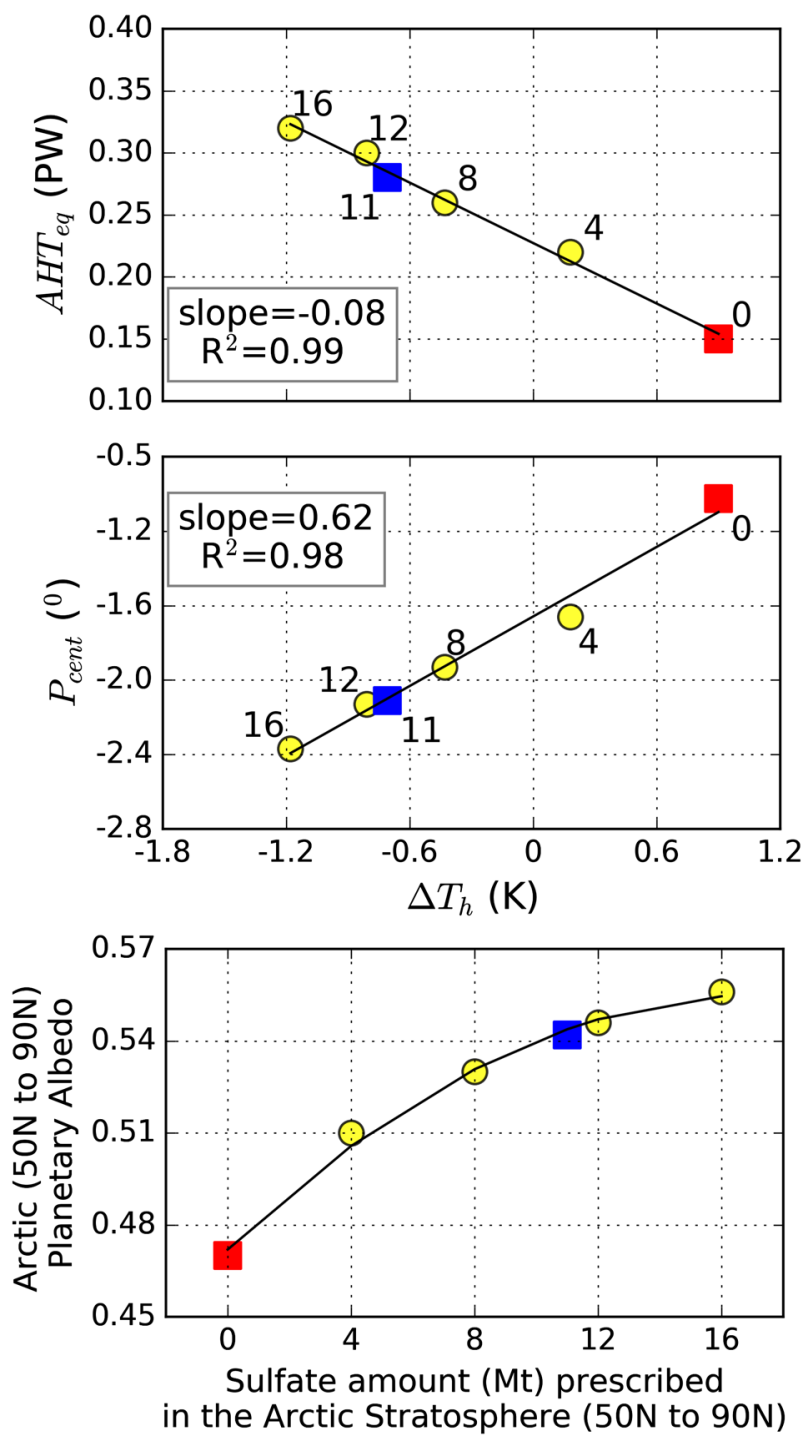

Fig. 8 a Annual mean northward atmospheric heat transport at the equator $\left(\mathrm{AHT}_{\mathrm{eq}}\right)$ vs annual mean inter-hemispheric temperature gradient $\left(\Delta \mathrm{T}_{\mathrm{h}}\right.$; annual mean northern hemisphere mean surface temperature minus southern hemisphere mean surface temperature, $\mathbf{b}$ annual mean ITCZ location $\left(\mathrm{P}_{\text {cent }}\right)$ vs annual mean inter-hemispheric temperature gradient for the Arctic geoengineering experiments with various aerosol loadings (in $\mathrm{Mt}$ ) which is indicated next to the points. c Planetary Albedo in the Arctic region $\left(50^{\circ} \mathrm{N}-90^{\circ} \mathrm{N}\right)$ vs amount of sulfate prescribed in the Arctic stratosphere. The red and blue squares indicate the $2 \mathrm{XCO} 2$ and ARCTIC cases, respectively

seasonal cycle of ITCZ location and its relation to the $\mathrm{AHT}_{\mathrm{eq}}$ and $\Delta \mathrm{T}_{\mathrm{h}}$. Further, we compare these seasonal shifts with the shifts in the annual mean location of ITCZ due to different geoengineering simulations. We note that in calculating monthly $\mathrm{AHT}_{\text {eq }}$ (denoted as $\mathrm{AHT}_{\text {eq, } \mathrm{m}}$ ), the steady state assumption used for calculating the annual mean AHT in Eq. (1) cannot be used and we need to include the storage terms. We calculate the atmospheric heat storage for monthly $\mathrm{AHT}_{\mathrm{eq}, \mathrm{m}}$ for a given month $m$ as (Donohoe et al. 2013):

$$
\begin{aligned}
A H T_{e q, m}= & <Q_{T_{O A}>_{m}-<Q_{S}>_{m}} \\
- & \frac{\left.<S T O R A G E\rangle_{(m+1)}-<S T O R A G E\right\rangle_{(m-1)}}{\Delta t},
\end{aligned}
$$

where, $<\cdot>$ represent area-weighted integration over southern hemisphere, $\mathrm{Q}_{\mathrm{TOA}}$ and $\mathrm{Q}_{\mathrm{S}}$ are defined in Eq. (1), and $\Delta \mathrm{t}$ is time interval (2 months) and STORAGE represents the vertically integrated moist static energy stored in the atmosphere which is given by:

STORAGE $=\frac{1}{g} \int_{0}^{P_{s}}\left(L q+C_{p} T+g Z\right) d P$,

where $\mathrm{L}_{\mathrm{q}}, \mathrm{C}_{\mathrm{p}} \mathrm{T}$ and $\mathrm{gZ}$ are theatent heat energy, sensible heat energy, and potential energy ( $\mathrm{gZ}$ ), respectively. $\mathrm{L}$ is the latent heat of vaporization of water, $C_{P}$ is the heat capacity at constant pressure, $\mathrm{T}$ is the temperature, $\mathrm{g}$ is the acceleration due to gravity, $\mathrm{Z}$ is the geopotential height and $\mathrm{P}_{\mathrm{S}}$ is the surface pressure.

We find that the extent of variation of $\mathrm{P}_{\text {cent }}$ is from $8^{\circ} \mathrm{S}$ to $8^{\circ} \mathrm{N}$ on a seasonal timescale (Fig. 9) in the CTL case. Correspondingly, the $\mathrm{AHT}_{\text {eq }}$ varies from $\sim-2$ to $\sim 2 \mathrm{Wm}^{-2}$ and $\Delta \mathrm{T}_{\mathrm{h}}$ varies from $\sim-10$ to $\sim 10 \mathrm{~K}$. Similar to the annual mean values simulated for various amounts of sulfate aerosols in Arctic, we simulate strong relationship between $\mathrm{AHT}_{\mathrm{eq}}$ and $\Delta \mathrm{T}_{\mathrm{h}}\left(\mathrm{R}^{2}=0.90\right)$, and between $\mathrm{P}_{\text {cent }}$ and $\Delta \mathrm{T}_{\mathrm{h}}\left(\mathrm{R}^{2}=0.64\right)$ on the seasonal timescale. However, we find that the change in the annual mean values of $\mathrm{AHT}_{\mathrm{eq}}, \Delta \mathrm{T}_{\mathrm{h}}$ and $\mathrm{P}_{\text {cent }}$ in the geoengineering and $2 \mathrm{XCO} 2$ simulations relative to the $\mathrm{CTL}$ case is very small when compared to these seasonal variations (Fig. 9; Table 5). We discuss the seasonal changes in $\mathrm{AHT}_{\mathrm{eq}}, \Delta \mathrm{T}_{\mathrm{h}}$ and $\mathrm{P}_{\text {cent }}$ in our three geoengineering and $2 \mathrm{XCO} 2$ simulations relative to the CTL case in the caption of Online Resource1: Figure S8.

\subsection{Effects of stratospheric warming on zonal winds}

The sulfate aerosols prescribed in the stratosphere tend to cool the surface by reflecting part of the solar radiation back to space, thereby reducing the radiation reaching the surface. Apart from this, these aerosols tend to warm the stratospheric regions where they are prescribed by absorbing the solar radiation in the near-infrared spectrum (single scattering albedo of sulfate aerosol is $~ 0.9$ ). Various effects of this stratospheric temperature change such as changes in the mid-latitude jet streams (Ferraro et al. 2015), stratospheric temperature, water vapor, ozone depletion (Tilmes et al. 2009), Quasi-biennial Osciallation (Aquila et al. 2014) etc. have been discussed in many previous studies. In 

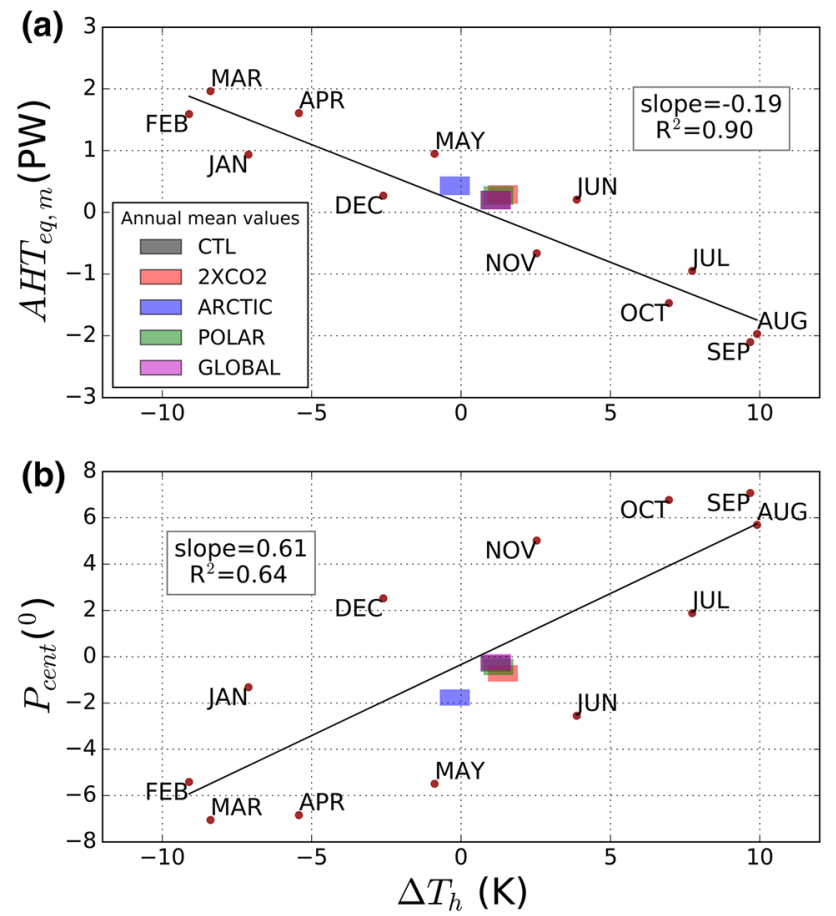

Fig. 9 a Monthly mean northward atmospheric heat transport at the equator $\left(\mathrm{AHT}_{\mathrm{eq}, \mathrm{m}}\right)$ vs monthly mean inter-hemispheric temperature gradient $\left(\Delta \mathrm{T}_{\mathrm{h}}\right.$; monthly mean northern hemisphere mean surface temperature minus southern hemisphere mean surface temperature), b monthly mean ITCZ location $\left(\mathrm{P}_{\text {cent }}\right)$ vs monthly mean inter-hemispheric temperature gradient in the CTL case and the annual mean positions for the CTL, 2XCO2, ARCTIC, POLAR and GLOBAL cases. Note that the CTL case (gray) and the GLOBAL case (magenta) annual means are nearly same and hence they overlap. Values of annual means of the three quantities can be found in Table 5

this section, we discuss the effect of stratospheric aerosols prescribed in our simulations on the stratospheric temperature changes and corresponding changes in the zonal winds in the upper troposphere and stratosphere.

In the $2 \mathrm{XCO} 2$ case, we simulate an accelerated stratospheric jet in both Arctic and Antarctic regions which is consistent with $\mathrm{CO}_{2}$ induced zonal mean zonal wind changes discussed in previous studies (Fig. 10a, b; Wu et al. 2011; Ferraro et al. 2015). For the ARCTIC and POLAR cases, we first discuss the temperature and zonal wind anomalies relative to the 2XCO2 case (Online Resource 1: Figure S9) in order to analyse the exclusive effect of geoengineering as discussed in Sect. 3.2. In the ARCTIC and POLAR cases, the heating of the stratosphere due to the aerosols prescribed in the polar regions is maximum during the respective hemisphere's summertime. During $\mathrm{NH}$ summer (JJA), we simulate a maximum warming of $\sim 12 \mathrm{~K}$ (Online Resource 1: Figure S9a, c) in the Arctic stratosphere (between 78.8 and $9.8 \mathrm{hPa}$ ) due to a large concentration of sulfate aerosols (up to $\sim 2000 \mu \mathrm{g} \mathrm{kg}^{-1}$ ) in both ARCTIC and POLAR cases. Similarly, during
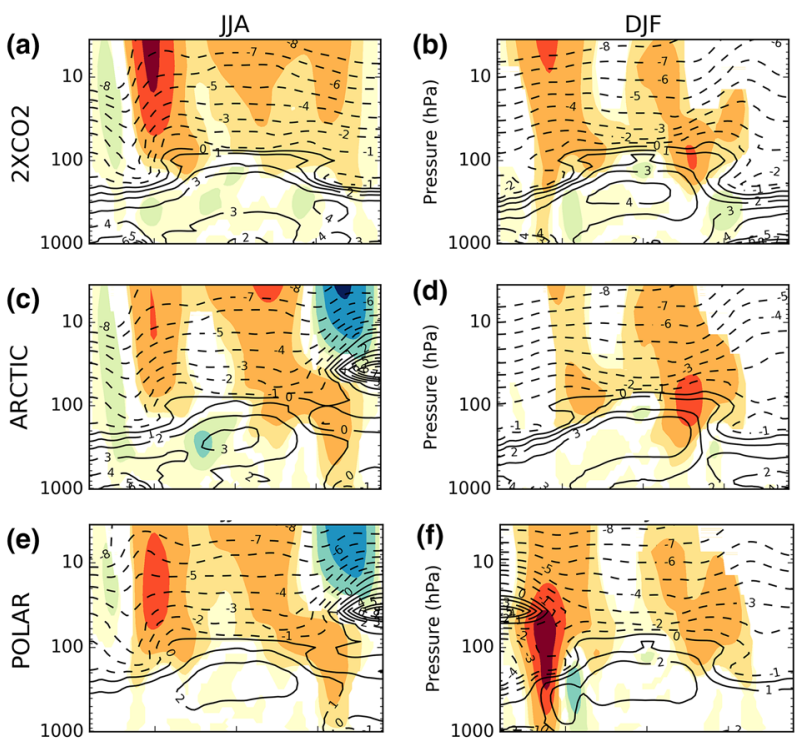

(g)

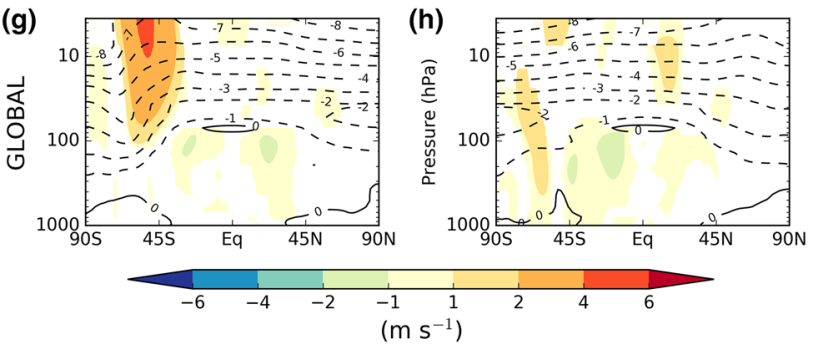

Fig. 10 Zonal mean temperature (contour lines) and zonal wind (colored shadings) anomalies during JJA and DJF seasons in the 2XCO2, ARCTIC, POLAR and GLOBAL cases relative to the CTL case. White areas are not significant (wind changes) at the 5\% significance level estimated using student's t-test for 60 annual means and standard error corrected for autocorrelation (Zweirs and von Storch 1995)

SH summer (DJF), there is a maximum warming of $\sim 9 \mathrm{~K}$ (Online Resource 1: Figure S9) in the Antarctic stratosphere in the POLAR case. However, in both the cases, there is no warming in the tropical stratosphere (Online Resource 1: Figure S9a, S9c), and hence the equatorto-pole temperature gradient at levels above $30 \mathrm{hPa}$ is reduced (Online Resource1: Figure S9a, S9c). As a result of this, we simulate a slowdown (up to $\sim 11 \mathrm{~ms}^{-1}$ ) of polar stratospheric westerly jet above the $30 \mathrm{hPa}$ level (Online Resource 1: Figure S9a, c). Similar slowdown in zonal winds is simulated for the $\mathrm{SH}$ but with a much weaker magnitude.

We also simulate a strengthening of the mid-latitude jets in the troposphere (between 500 and $100 \mathrm{mb}$ ) by up to $3 \mathrm{~ms}^{-1}$ in the $\mathrm{NH}$ mid-latitudes during the NH summer in both the ARCTIC and POLAR cases (Online Resource 1: Figure S9a, c). We notice similar changes in the SH midlatitude zonal winds during SH summer $\left(\sim 4 \mathrm{~ms}^{-1}\right)$, but only in the POLAR case. This intensification of winds in the 
mid-latitudes is associated with an increased upper tropospheric equator-to-pole temperature gradient caused by the residual warming in the tropical troposphere and cooling in the polar troposphere (Online Resource 1: Figure S9a-d). In the GLOBAL case, there is relatively less sulfate aerosol concentration in the polar regions and hence less stratospheric warming than the ARCTIC and POLAR cases. As a result of this, the magnitude of the wind changes simulated in the GLOBAL case (Online Resource 1: Figure S9e, f) is much smaller compared to the ARCTIC and POLAR cases (Online Resource 1: Figure S9a-d).

We now discuss Fig. 10c-h which show the combined effect of $\mathrm{CO}_{2}$ doubling and geoengineering in the geoengineering simulations as the anomalies are relative to the CTL case. We simulate a marginal slowdown in the Arctic stratospheric vortex during JJA in both ARCTIC and POLAR cases (Fig. 10c, e). In the troposphere, however, there is an increase in the equator to pole temperature gradient (because of the residual warming in the tropics) during summertime corresponding to an accelerated jet stream (Fig. 10c-f), which could possibly reduce the number of weather extremes in the mid-latitudes (Francis and Vavrus 2012). The anomaly in zonal winds relative to the CTL case is the least in the GLOBAL case (Fig. 10g, h) since the change in meridional temperature gradients are the least: jets are more like in the CTL case.

\subsection{Stratospheric water vapor response}

The increase in stratospheric water vapor could lead to depletion of stratospheric ozone as stratospheric water vapor can alter the $\mathrm{HO}_{\mathrm{x}}$ cycle (Tilmes et al. 2009; Kravitz et al. 2012). As shown in several previous studies (e.g. Manabe et al. 1975), temperature decreases in the stratosphere in the $2 \mathrm{XCO} 2$ case. However, water vapor increases at all levels in the stratosphere and by up to $20 \%$ at around $120 \mathrm{hPa}$ in the $2 \mathrm{XCO} 2$ case (Fig. 11). This shows that, unlike tropospheric water vapor changes where specific humidity changes are controlled by temperature (via the Clausius-Clapeyron relation), the stratospheric water vapor changes are not constrained by stratospheric temperature changes. Instead, stratospheric water vapor changes are likely governed by tropical tropospheric temperature changes: we find a 35\% increase in total stratospheric water vapor (Online Resource 1: Figure S10) for a tropical mean surface warming of $\sim 2.1 \mathrm{~K}$ (Table 3 ) relative to the CTL case. This is because in the $2 \mathrm{XCO} 2$ case, the troposphere is warmer which leads to transport of more tropospheric water vapor from the tropical troposphere to the stratosphere (Sherwood et al. 2010; Feuglistaler et al. 2009), and hence we find that the stratospheric water vapor increase scales with the tropical mean surface warming.

We simulate global mean tropospheric cooling due to both regional (ARCTIC and POLAR) and global (GLOBAL) geoengineering experiments relative to the 2XCO2 case (Online Resource 1: Figure S11). Because of this cooling, the stratospheric water vapor is reduced in our geoengineering simulations though the stratosphere (above $100 \mathrm{hPa}$ ) is warmer (Online Resource 1: Figure S11c). The tropospheric cooling and hence the reduction in stratospheric water vapor are larger in the GLOBAL case than the ARCTIC and POLAR cases. Thus, the GLOBAL case is more likely to offset the stratospheric ozone depletion caused by a $\mathrm{CO}_{2}$ doubling (and the related increase in stratospheric water vapor) than the ARCTIC and POLAR cases.

There is a residual increase in the tropospheric temperature in the ARCTIC and POLAR cases relative to the CTL case (Fig. 11). Correspondingly, there is a residual increase in stratospheric water vapor in the ARCTIC and POLAR cases: the total amount of stratospheric water vapor increases by 28 and 30\% in the ARCTIC and POLAR case, respectively. This residual tropospheric warming is not simulated in the GLOBAL case. Instead, there is a slight cooling of about $0.5 \mathrm{~K}$ near the tropical tropopause layer and an associated decrease in water vapor (Fig. 11). It should be noted that the prescribed sulfate aerosols in the GLOBAL
Fig. 11 Vertical profile of changes in specific humidity $\left(\mathrm{mg} \mathrm{kg}^{-1} ; \mathbf{a}\right)$, percentage changes in specific humidity $(\%$, b) and changes in temperature $(\mathrm{K}, \mathbf{c})$ in the upper atmosphere (120-3 hPa) in the ARCTIC, POLAR and GLOBAL cases relative to the CTL case

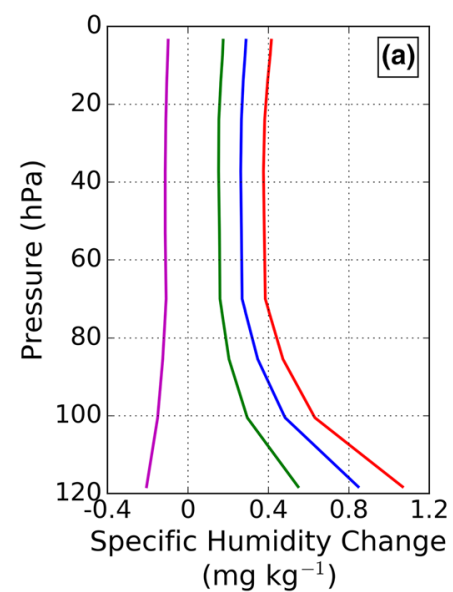

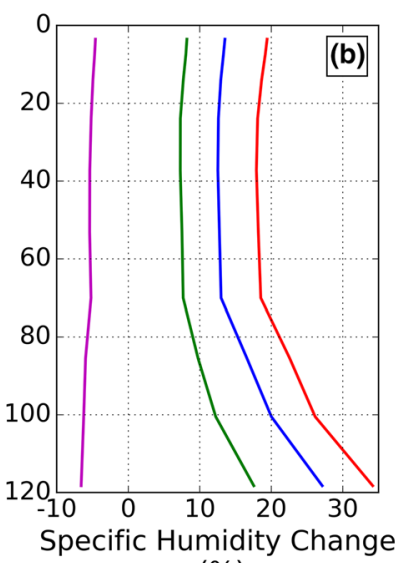

(\%)

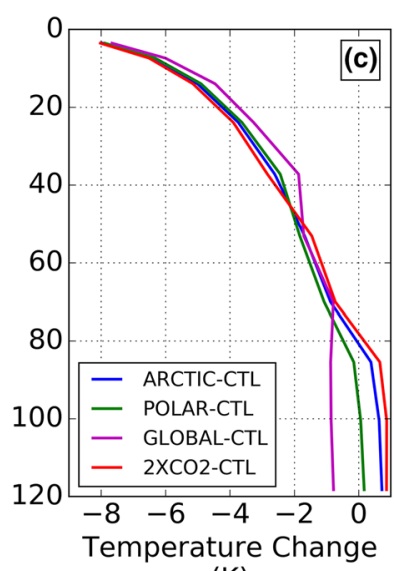

(K) 
case are much above the tropical tropopause layer (Fig. 1) and hence the GLOBAL case does not simulate warming near the tropical tropopause layer due to near-IR absorption by prescribed sulfate aerosols.

\subsection{Prescription of sulfate aerosols during summer}

In our ARCTIC and POLAR simulations, we have prescribed the stratospheric sulfate aerosols throughout the year. However, the effective negative radiative forcing in these cases is only seen during the sunlit months of the polar regions (Fig. 12). Further, the sulfate aerosols in the Arctic stratosphere have a residence time of only 3 months (Robock et al. 2008). MacCracken (2009), therefore, suggested that Arctic geoengineering only be implemented during the sunlit months of the Arctic. In practice, there is probably no need for implementation during the spring when the surface is ice and snow covered (though this could change by the time the atmospheric $\mathrm{CO}_{2}$ doubles).
The reduction in the duration of implementation is likely to cut the cost of implementing geoengineering by approximately half.

The comparison of the simulation with prescription of aerosols during sunlit months to year-long prescription shows that there are no substantial differences in either the radiative forcing (Fig. 12) or temperature change (Fig. 13) between the two simulations (Tables 2, 3, 4, 5). However, we note that the global mean radiative forcing for prescription only during sunlit months is larger (Fig. 12) by 0.56 and $0.73 \mathrm{Wm}^{-2}$ for Arctic and Polar geoengineering cases, respectively. This is because of the residual solar radiative forcing during the Spring and Autumn in the respective high latitudes which results in a slightly larger residual annual mean warming $(\sim 0.5 \mathrm{~K})$ in the polar regions in the cases with prescription only during sunlit months (Table 3). We also find that the precipitation changes in the monsoon regions in the simulation with prescription of aerosols during sunlit months and year-long prescription
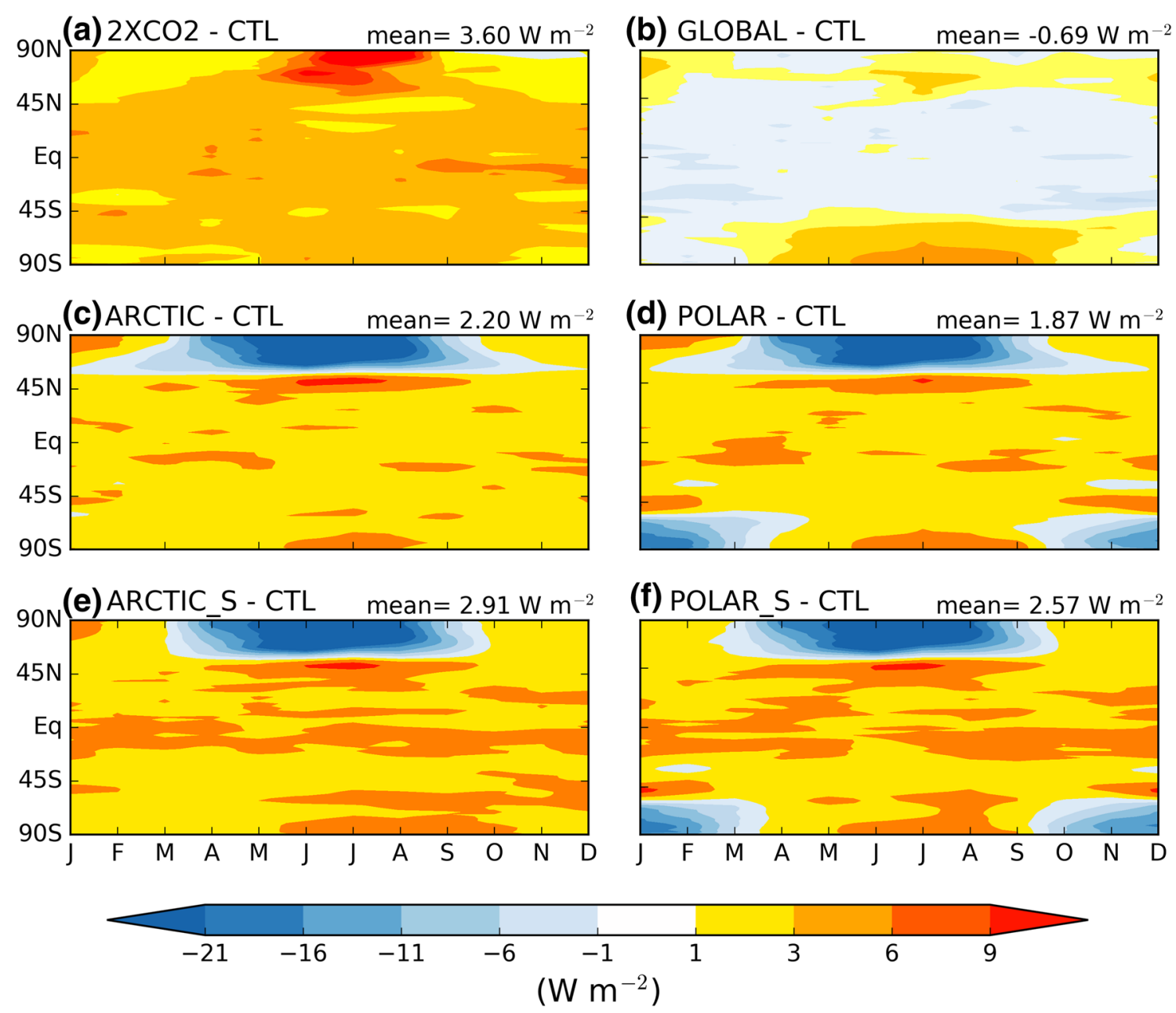

Fig. 12 Monthly variation in latitudinal profile of radiative forcing in a 2XCO2, b GLOBAL, $\mathbf{c}$ ARCTIC, d POLAR, e ARCTIC_S, f POLAR_S cases relative to the CTL case 

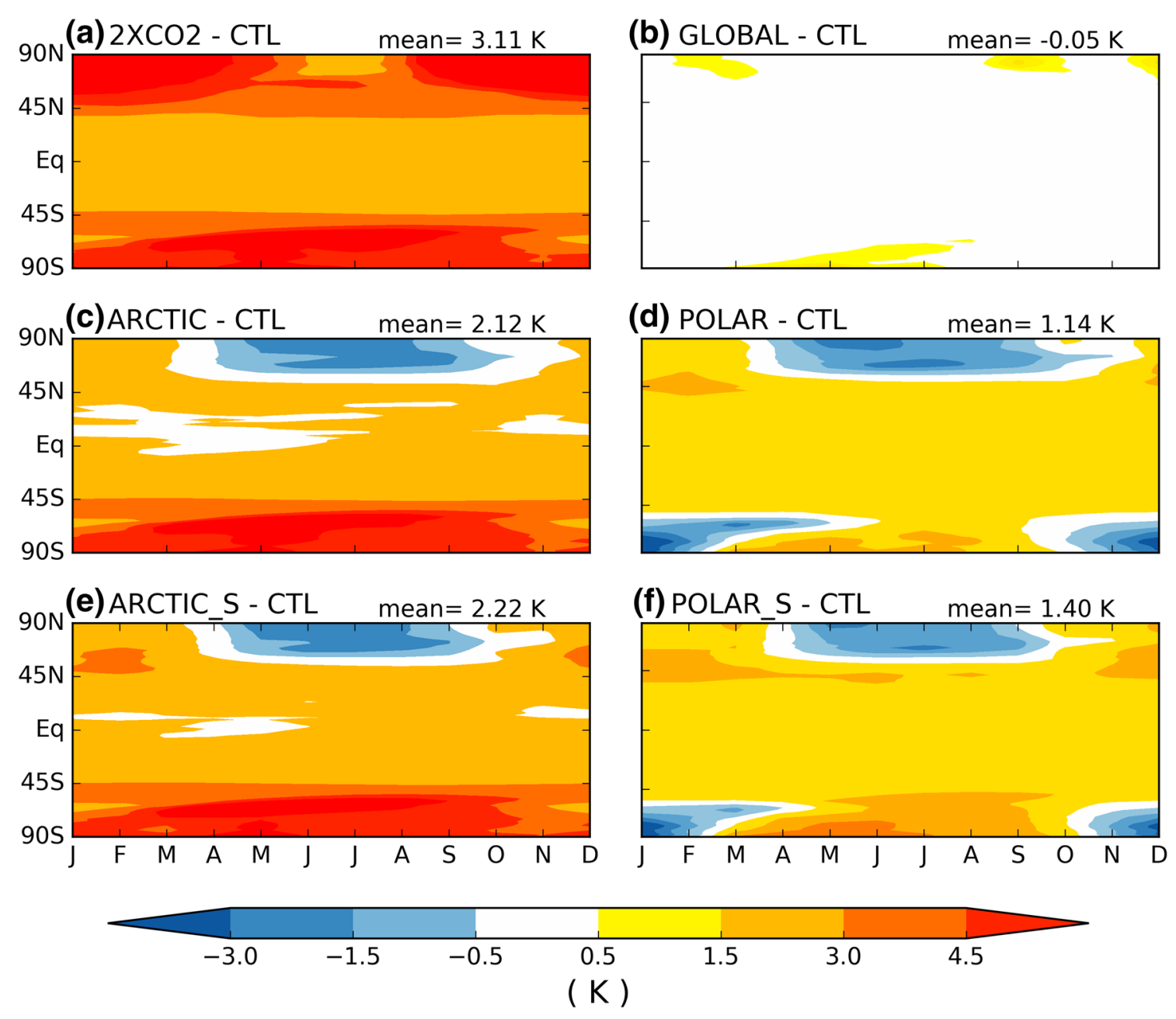

Fig. 13 Monthly variation in latitudinal profile of surface temperature anomaly in a 2XCO2, b GLOBAL, c ARCTIC, d POLAR, e ARCTIC_S and $\mathbf{f}$ POLAR_S cases relative to the CTL case

are similar (Online Resource1: Figure S12). This suggests that prescription of aerosols during the sunlit months of the polar regions is sufficient to ameliorate the Arctic climate change.

\section{Discussion and conclusion}

In this study, we investigate the precipitation response in the tropical monsoon regions to ARCTIC, POLAR (geoengineering in both Arctic and Antarctic) and GLOBAL geoengineering, by prescribing stratospheric sulfate aerosols in a $2 \mathrm{XCO} 2$ world, such that the Arctic, Polar and Global mean surface temperatures are restored to pre-industrial levels, respectively. In the ARCTIC case, aerosols are prescribed poleward of $50^{\circ} \mathrm{N}$, poleward of $50^{\circ} \mathrm{N}$ and $50^{\circ} \mathrm{S}$ in the POLAR case and uniformly around the globe in the GLOBAL case. We simulate precipitation increases in all monsoon regions for $\mathrm{CO}_{2}$ doubling, except in the North
American region. In the ARCTIC case, the ITCZ shifts southward by $1.5^{\circ}$ causing a precipitation decrease in the in $\mathrm{NH}$ monsoon regions (up to $-12 \%$ ) and increase in the $\mathrm{SH}$ monsoon regions relative to the CTL case (up to $+17 \%$ ).

This ITCZ shift due to Arctic geoengineering could be reduced by geoengineering the southern hemisphere simultaneously (MacCracken et al. 2013) and the ITCZ location can be tuned by varying the Arctic and Antarctic forcing (Kravitz et al. 2016). In agreement with these earlier studies, the ITCZ shift in the ARCTIC case is nearly offset in the POLAR case. This near restoration of ITCZ position in the POLAR case reduces the reduction in precipitation in $\mathrm{NH}$ monsoon regions and increase in $\mathrm{SH}$ monsoon regions that are simulated in the ARCTIC case. The annual mean precipitation increases in most monsoon regions by up to $7 \%$ in this case which is mainly due to the residual $\mathrm{CO}_{2}$ induced warming in the tropics. In the GLOBAL case, there is very little ITCZ shift and precipitation changes in 
most monsoon regions are within $\pm 2 \%$, as the $\mathrm{CO}_{2}$ induced warming in the tropics are nearly offset in this case.

The ITCZ shifts are associated with changes in $\mathrm{AHT}_{\mathrm{eq}}$ as shown in many previous studies (Donohoe et al. 2013; Frierson and Hwang 2011; McGee et al. 2013). We find an increase in northward $\mathrm{AHT}_{\mathrm{eq}}$ in the ARCTIC and POLAR cases relative to the CTL case, and this increase is associated with the southward shift in ITCZ. The ARCTIC and POLAR simulations show large increases in poleward atmospheric heat transport anomalies mainly in the midlatitudes which is likely contributed by increased poleward latent heat flux due to the residual warming in the tropical regions (Tilmes et al. 2014). In the GLOBAL case, there is no significant change in the latitudinal distribution of poleward atmospheric heat transport and consequently very little change in $\mathrm{AHT}_{\text {eq }}$. Correspondingly, we simulate almost no shift in the ITCZ in the GLOBAL case.

Some previous studies have also reported results that are similar to our findings here. For instance, MacCracken et al. (2013) found that Arctic geoengineering by solar insolation reduction in Arctic region would cause negative (positive) zonal mean precipitation anomalies in the $\mathrm{NH}$ $(\mathrm{SH})$ tropics due to southward shift in ITCZ location. They further showed that when equal amount of insolation reduction is imposed in both Arctic and Antarctic regions these anomalies are reduced, keeping the ITCZ position more or less in place. Kravitz et al. (2016) showed that a system can be designed such that the changes in Arctic temperatures are offset and the shifts in the tropical precipitation centroid are simultaneously minimized for two degrees of freedom: amount of solar reductions in Arctic and Antarctic. Some studies such as Ban-Weiss and Caldeira (2010) found that a symmetric polar weighting of solar insolation reduction or sulfate aerosol prescription is required in order to minimize the changes in both temperature and precipitation patterns. For several symmetric distributions of aerosols between $\mathrm{SH}$ and NH but with a fixed amount of total global aerosol amount, Modak and Bala (2014) found almost no shift in the ITCZ location. MacMartin et al. (2013) showed that by adjusting the spatial and temporal reductions in solar insolation, various optimization objectives such as minimizing residual global mean warming, residual mean temperature and precipitation changes in the Giorgi regions can be achieved. Kravitz et al. (2016) showed that multiple climate constraints can be satisfied simultaneously using an equal number of degrees of freedom as that of the constraints.

Since we prescribe a large concentration of sulfate aerosols in the polar stratosphere, we simulate a large stratospheric warming in the regions where aerosols are prescribed. Because of this large local heating we find a strong reduction in zonal wind speed in the stratosphere above $30 \mathrm{hPa}$ and enhancement in the upper troposphere wind in the NH mid-latitudes during $\mathrm{NH}$ summers. The magnitude of wind changes due to the ARCTIC and POLAR cases is much larger than the wind changes in the GLOBAL case (Fig. 10). The residual surface and upper tropospheric warming in the ARCTIC and POLAR cases leads to larger amount of water vapor changes in the stratosphere compared to the GLOBAL case. This could potentially lead to ozone depletion (Tilmes et al. 2009) as well as more global warming due to stratospheric water vapor feedback (Dessler et al. 2013) in the ARCTIC and POLAR cases.

There are several limitations to our modelling study. Our simulations are idealized equilibrium experiments designed to illustrate the basic mechanisms associated with the remote effects of Arctic geoengineering and hence may not mimic the real world accurately. Further, as our simulations are idealized and only meant to understand the processes involved in altering the tropical precipitation patterns for regional/global geoengineering, we impose a larger forcing (e.g. we double $\mathrm{CO}_{2}$ concentration) so the climate change signal would be large. Our model lacks deep ocean feedbacks and a dynamic sea-ice and hence the ocean heat transport changes due to $\mathrm{CO}_{2}$ increase and geoengineering and the transient effects are not modelled realistically in our simulations. Also, the spatial pattern of ocean heat uptake that has an effect on surface warming and net forcing patterns (Armour et al. 2012) has not been considered in our simulations. The carbon and other biogeochemical cycle components are not included in our simulations and hence the feedbacks between climate and biogeochemical cycles are missing in our simulations.

We have not injected the aerosols into the stratosphere, rather we prescribe them. Therefore, our simulations lack the microphysics of aerosol evolution and transport of aerosols. The smoothly increasing prescription of aerosols from $50^{\circ}$ latitude to the pole in the ARCTIC and POLAR cases (see Sect. 2.1) and the uniform prescription in the GLOBAL case may not be achievable in the real world because of the stratospheric circulations such as Brewer Dobson circulation which could influence both the horizontal and vertical distribution of aerosols in the stratosphere (Ferraro et al. 2015). For instance, a recent study (Jackson et al. 2015) of Arctic Geoengineering using HadGEM2 by emission of sulfate aerosols at $78^{\circ} 55^{\prime} \mathrm{N}$ finds that aerosols spread across the $\mathrm{NH}$ all the way to the equator. It is also important to note that the prescription of sulfate aerosols in the Antarctic region for the POLAR case is not optimal as pointed out in Sect. 3.1. A much more effective approach would be to concentrate more aerosols at latitudes where there is sea-ice. This requires a well-tuned profile of latitudinal distribution of aerosols that could be achieved by tropospheric approaches (MacCracken 2016). The Globally uniform geoengineering may also not be optimal as the climate sensitivity in this case is much smaller compared to 
the regional climate sensitivity of Arctic and Polar geoengineering methods (MacCracken et al. 2013).

Presence of sulfate aerosols in stratosphere also has adverse effects on stratospheric ozone chemistry (Tilmes et al. 2009), especially with the prescription of sulfate in the ARCTIC and POLAR cases as more sulfate is concentrated in the polar regions. We do not model these effects of stratospheric sulfate aerosols on ozone chemistry. However, it has been suggested that the ozone depletion effects due to stratospheric geoengineering can be reduced or even reversed when alkaline metal salts are injected (Keith et al. 2016). Further, we have used a single climate model in this study. Although our results are consistent with previous studies, we suggest a multi-model study of Arctic and Polar geoengineering for testing the robustness of our results and estimate the uncertainty. We also suggest further research be done on other approaches considered for regional geoengineering such as tropospheric sulfate injection (MacCracken 2016).

Despite these shortcomings in our study, we believe that our results are qualitatively robust. Even with improvements in model simulations by including the complexities such as deep ocean dynamics, dynamic sea-ice, aerosol transport, aerosol indirect effects, the robustness of our main results such as the southward shifting of ITCZ due to Arctic geoengineering is likely to hold. Further studies related to Arctic geoengineering such as extreme event analysis, effect on vegetation response, etc. could be the subject for future investigations to further improve our understanding of the effects of Arctic geoengineering.

In summary, Arctic geoengineering would shift the ITCZ southward causing precipitation reduction in the $\mathrm{NH}$ monsoon regions and increase in the SH monsoon regions. This shift in ITCZ location can be reduced by geoengineering both Arctic and Antarctic regions: we do simulate much smaller precipitation changes in both $\mathrm{NH}$ and $\mathrm{SH}$ monsoon regions compared to those resulting from geoengineering only the Arctic. Geoengineering with uniform prescription of sulfate aerosol concentration across the globe is associated with a much smaller precipitation change in both $\mathrm{NH}$ and SH monsoon regions when compared to Arctic and Polar geoengineering, as the ITCZ does not shift and the residual $\mathrm{CO}_{2}$ induced warming in the tropics is the least. Further, the changes in zonal winds and stratospheric water vapor relative to the pre-industrial climate are much smaller when aerosols are uniformly prescribed around the globe. Based on our results we infer that both ITCZ shift and residual $\mathrm{CO}_{2}$ induced warming in the tropics could result in precipitation changes relative to the pre-industrial climate in the monsoon regions: (1) Arctic geoengineering causes large remote effects (southward ITCZ shift) and also leaves $\mathrm{CO}_{2}$ induced warming in the tropics leading to large precipitation decreases (increases) in the $\mathrm{NH}(\mathrm{SH})$ monsoon regions, (2) Polar geoengineering nearly restores the ITCZ location but leaves $\mathrm{CO}_{2}$ induced warming in the tropics leading to substantial precipitation increases in most of the monsoon regions, and (3) Global geoengineering does not shift ITCZ and also nearly offsets the warming in the tropical regions resulting in little precipitation changes in the monsoon regions.

Acknowledgements We acknowledge the financial support given by the Department of Science and Technology (DST), Government of India for enhancing the climate change related research activities. The first and third authors acknowledge the scholarships provided by the Indian Institute of Science. We also thank the two anonymous reviewers for their valuable comments that helped us to improve our manuscript. Simulations were performed on the supercomputer at the Centre for Atmospheric and Oceanic Sciences which was funded by the Fund for Improvement of S\&T infrastructure (FIST) by DST and the Divecha Centre for Climate Change.

Open Access This article is distributed under the terms of the Creative Commons Attribution 4.0 International License (http:// creativecommons.org/licenses/by/4.0/), which permits unrestricted use, distribution, and reproduction in any medium, provided you give appropriate credit to the original author(s) and the source, provide a link to the Creative Commons license, and indicate if changes were made.

\section{References}

Aquila V, Garfinkel CI, Newman PA, Oman LD, Waugh DW (2014) Modifications of the quasi-biennial oscillation by a geoengineering perturbation of the stratospheric aerosol layer. Geophys Res Lett 41:1738-1744. doi:10.1002/2013GL058818

Armour Kyle C, Bitz MC, Roe GH (2012) Time-varying climate sensitivity from regional feedbacks. J Clim 26:4518-4534. doi:10.1175/JCLI-D-12-00544.1

Bala G (2009) Problems with geoengineering schemes to combat climate change. Curr Sci India 96:41-48

Bala G, Duffy PB, Taylor KE (2008) Impact of geoengineering schemes on the global hydrological cycle. Proc Natl Acad Sci USA 105:7664-7669. doi:10.1073/pnas.0711648105

Bala G, Caldeira K, Nemani R (2010) Fast versus slow response in climate change: implications for the global hydrological cycle. Clim Dyn 35:423-434. doi:10.1007/s00382-009-00583-y

Ban-Weiss GA and Caldeira K (2010) Geoengineering as an optimization problem. Environ Res Lett 5:034009. doi:10.1088/1748-9326/5/3/034009

Broccoli AJ, Dahl KA, Stouffer RJ (2006) Response of the ITCZ to Northern Hemisphere cooling. Geophys Res Lett 33(1):L01702. doi:10.1029/2005GL024546

Budkyo MI (1974) Climate and life. Academic Press, New York

Caldeira K, Wood L (2008) Global and Arctic climate engineering: numerical model studies. Philos Trans R Soc A 366:4039-4056. doi:10.1098/rsta.2008.0132

Caldeira K, Bala G, Cao L (2013) The science of geoengineering. Annu Rev Earth Planet Sci 41:231-56. doi:10.1146/ annurev-earth-042711-105548

Cao L, Bala G, Caldeira K (2012) Climate response to changes in atmospheric carbon dioxide and solar irradiance on the time scale of days to weeks. Environ Res Lett 7:034015. doi:10.1088/1748-9326/7/3/034015 
Cao L, Duan L, Bala G, Caldeira K (2016) Simulated long-term climate response to idealized solar geoengineering. Geol Res Lett 43:2209-2217. doi:10.1002/2016GL068079

Chiang J, Bitz C (2005) The influence of high latitude ice on the position of the marine intertropical convergence zone. Clim Dyn 25(5):477-496

Christensen JH, Hewitson B, Busuioc A, Chen A, Gao X, Held I, Jones R, Kolli RK, Kwon W-T, Laprise R, Magaña Rueda V, Mearns L, Menéndez CG, Räisänen J, Rinke A, Sarr A, Whetton P (2007) Regional Climate Projections. In: Solomon S, Qin D, Manning M, Chen Z, Marquis M, Averyt KB, Tignor M, Miller HL (eds) Climate change 2007: the physical science basis. Contribution of Working Group I to the Fourth Assessment Report of the Intergovernmental Panel on Climate Change. Cambridge University Press, Cambridge

Christensen et al (2013) Climate phenomena and their relevance for future regional climate change. In: Stocker TF, Qin D, Plattner GK, Tignor M, Allen SK, Boschung J, Nauels A, Xia Y, Bex V, Midgley PM (eds) Climate change 2013: the physical science basis. Contribution of Working Group I to the Fifth Assessment Report of the Intergovernmental Panel on Climate Change. Cambridge University Press, Cambridge

Collins et al (2013) Long-term climate change: projections, commitments and irreversibility. In: Stocker TF, Qin D, Plattner GK, Tignor M, Allen SK, Boschung J, Nauels A, Xia Y, Bex V, Midgley PM (eds) Climate change 2013: the physical science basis. Contribution of Working Group I to the Fifth Assessment Report of the Intergovernmental Panel on Climate Change. Cambridge University Press, Cambridge

Crutzen PJ (2006) Albedo enhancement by stratospheric sulfur injections:a contribution to resolve a policy dilemma? Clim Change 77:211-220. doi:10.1007/s10584-006-9101-y

Dessler AE, Schoeberl MR, Wang T, Davis SM, Rosenlof KH (2013) Stratospheric water vapor feedback. Proc Nat Acad Sci 110:18087-18091. doi:10.1073/pnas.1310344110

Devaraju N, Bala G, Modak A (2015) Effects of large-scale deforestation on precipitation in the monsoon regions: remote versus local effects. Proc Natl Adac Sci USA. doi:10.1073/pnas.1423439112

Donohoe A, Marshall J, Ferreira D, McGee D (2013) The relationship between ITCZ location and cross-equatorial atmospheric heat transport: from the seasonal cycle to the Last Glacial Maximum. J Clim 26(11):3597-3618

Duarte CM, Lenton TM, Wadhams P, Wassmann P (2012) Abrupt climate change in the Arctic. Nat Clim Change 2:60-62

Ferraro AJ, Charlton-Perez AJ, Highwood EJ (2015) Stratospheric dynamics and midlatitude jets under geoengineering with space mirrors and sulfate and titania aerosols. J Geophys Res-Atmos 120:414-429. doi:10.1002/2014JD022734

Francis JA, Vavrus SJ (2012) Evidence linking Arctic amplification to extreme weather in mid-latitudes. Geophys Res Lett 39:L06801. doi:10.1029/2012GL051000

Frierson DMW, Hwang YT (2012) Extratropical influence on ITCZ shifts in slab ocean simulations of global warming. J Clim 25(2):720-733

Fueglistaler S et al (2009) The tropical tropopause layer. Rev Geophys 47:RG1004. doi:10.1029/2008RG000267

Govindasamy B, Caldeira K (2000) Geoengineering earth's radiation balance to mitigate $\mathrm{CO}_{2}$-induced climate change. Geophys Res Lett 27:2141-2144. doi:10.1029/1999GL006086

Govindasamy B, Caldeira K, Duffy PB (2003) Geoengineering earth's radiation balance to mitigate climate change from a quadrupling of $\mathrm{CO}_{2}$. Glob Planet Change 37(1-2):157-168

Graf HF (1992) Arctic radiation deficit and climate variability. Clim Dyn 7:19-28
Hansen J, Sato M, Ruedy R (1997) Radiative forcing and climate response. J Geophys Res 02(D6):6831-6864. doi:10.1029/96JD03436

Haywood JM, Jones A, Bellouinand N, Stephenson D (2013) Asymmetric forcing from stratospheric aerosols impacts Sahelian rainfall. Nat Clim Change 3:660-665

Held IM, Soden BJ (2006) Robust responses of the hydrological cycle to global warming. J Clim 19:5686-5699. doi:10.1175/ JCLI3990.1

Holland MM, Bitz CM (2003) Polar amplification of climate change in coupled models. Clim Dyn 21:221-232. doi:10.1007/ s00382-003-0332-6

IPCC (2014) Climate change 2014: synthesis report. In: Core Writing Team, Pachauri RK, Meyer LA (eds) Contribution of Working Groups I, II and III to the Fifth Assessment Report of the Intergovernmental Panel on Climate Change. IPCC, Geneva, p 151

Jackson LS, Crook JA, Jarvis A, Leedal D, Ridgwell A, Vaughan N, Forster PM (2015) Assessing thecontrollability of Arctic sea ice extent by sulfate aerosol geoengineering. Geophys Res Lett 42:1223-1231. doi:10.1002/2014GL062240

Jeffries OM, Overland JE, Perovich DK (2013) The Arctic shifts to a new normal. Phys Today. doi:10.1063/PT.3.2147

Kalidindi S, Bala G, Modak A, Caldeira K (2014) Modeling of solar radiation management: a comparison of simulations using reduced solar constant and stratospheric sulfate aerosols. Clim Dyn 44:2909-2925. doi:10.1007/s00382-014-2240-3

Keith DW (2000) Geoengineering the climate: history and prospect. Annu Rev Energy Environ 25:245-284. doi:10.1146/annurev. energy.25.1.245

Keith DW, Weisenstein DK, Dykema JA, Keutsch FN (2016) Stratopsheric solar geoengineering without ozone loss. Proc Natl Acad Sci 113:14910-14914. doi:10.1073/pnas.1615572113

Kiehl JT, Schneider L, Rasch PJ, Barth C, Wong J (2000) Radiative forcing due to sulfate aerosols from simulations with the National Center for Atmospheric Research Community Climate Model, Version 3. J Geophys Res Atmos 105:1441-1457. doi:10 .1029/1999JD900495

Kravitz B, Robock A, Shindell DT, Miller MA (2012) Sensitivity of stratospheric geoengineering with black carbon to aerosol size and altitude of injection. J Geophys Res Atmos. doi:10.1029/2 011JD017341

Kravitz et al (2014) A multi-model assessment of regional climate disparities caused by solar geoengineering. Environ Res Lett 9:074013. doi:10.1088/1748-9326/9/7/074013

Kravitz B, MacMartin DG, Wang H, Rasch PJ (2016) Geoengineering as a design problem. Earth Syst Dyn 7:469-497. doi:10.5194/ esd-7-469-2016

Lenton TM, Vaughan NE (2009) The radiative forcing potential of different climate geoengineering options. Atmos Chem Phys 9:5539-5561

MacCracken MC (2009) On the possible use of geoengineering to moderate specific climate change impacts. Environ Res Lett. doi:10.1088/1748-9326/4/4/045107

MacCracken MC (2016) The rationale for accelerating regionally focused climate intervention research. Earth's Future. doi:10.10 02/2016EF000450

MacCracken MC, Shin HJ, Caldeira K, Ban-Weiss GA (2013) Climate response to imposed solar radiation reductions in high latitudes. Earth Syst Dyn 4:301-315, doi:10.5194/esd-4-301-2013

MacMartin DG, Keith DW, Kravitz B, Caldeira K (2013) Management of trade-offs in geoengineering through optimal choice of non-uniform radiative forcing. Nat Clim Change 3:365-368. doi:10.1038/NCLIMATE1722 
Manabe S, Wetherald TS (1975) The effects of doubling of $\mathrm{CO}_{2}$ concentration on the climate of a general circulation model. J Atmos Sci 32:3-15

McGee D, Donohoe A, Marshall J, Ferreira D (2013) Changes in ITCZ location and cross-quatorial heat transport at the last glacial maximum, Heinrich Stadial 1, and the mid-Holocene. Earth Planet Sci Lett 390:69-79

Modak A, Bala G (2014) Sensitivity of simulated climate to latitudinal distribution of solar insolation reduction in SRM geoengineering methods. Atmos Chem Phys 14:7769-7779. doi:10.5194/acp-14-7769-2014

Modak A, Bala G, Cao L, Caldeira K (2016) Why must a solar forcing be larger than a $\mathrm{CO}_{2}$ forcing to cause the same global mean surface temperature change? Environ Res Lett 11:044013. doi:10.1088/1748-9326/11/4/044013

Neale RB et al (2010) Description of the NCAR community atmosphere model (CAM 4.0) (Natl Cent Atmos Res, Boulder, CO), NCAR/TN-485 + STR

Neelin JD, Munnich M, Su H, Myerson JE, Holloway CE (2006) Tropical drying trends in global warming models and observations. Proc Natl Acad Sci USA 103:6110-6115. doi:10.1073/ pnas. 060179810

Niemeier U, Timmreck C (2015) What is the limit of stratospheric sulfur climate engineering? Atmos Chem Phys 15(9129):9141. doi:10.5194/acp-15-9129-2015

NRC (National Research Council) Report (2015) Climate intervention: reflecting sunlight to cool earth. The National Academies Press, Washington

Oman, L, Robock A, Stenchikov G, Schmidt GA, Ruedy R (2005) Climatic response to high latitude volcanic eruptions. J Geophys Res 110:D13103. doi:10.1029/2004JD005487

Pitari et al (2014) Stratospheric ozone response to sulfate geoengineering: results from the Geoengineering Model Intercomparison Project (GeoMIP). J Geophys Res Atmos 119:2629-2653. doi:10.1002/2013JD020566

Pithan F, Mauritsen T (2014) Arctic amplification dominated by temperature feedbacks in contemporary climate models. Nat Geosci 7:181-184. doi:10.1038/ngeo2071

Robock A, Oman L, Stenchikov GL (2008) Regional climate responses to geoengineering with tropical and Arctic $\mathrm{SO}_{2}$ injections. J Geophys Res 113:D16101. doi:10.1029/2008JD010050

Schmidt et al (2012) Solar irradiance reduction to counteract radiative forcing from a quadrupling of $\mathrm{CO}_{2}$ : climate responses simulated by four earth system models. Earth Syst Dyn 3:63-78. doi:10.5194/esd-3-63-2012
Shephard J et al (2009) Geoengineering the climate: science, governance and uncertainty. The Royal Society

Sherwood SC, Roca R, Weckwerth TM, Andronova NG (2010) Tropospheric water vapor, convection, and climate. Rev Geophys 48:RG2001. doi:10.1029/2009rg000301

Stenchikov G, Robock A, Ramaswamy V, Schwarzkopf MD, Hamilton K, Ramachandran S (2002) Arctic oscillation response to the 1991 Mount Pinatubo eruption: effects of volcanic aerosols and ozone depletion. J Geophys Res. doi:10.1029/2002JD002090

Stroeve JC et al (2012) Trends in Arctic sea ice extent from CMIP5, CMIP3 and observations. doi:10.1029/2012GL052676

Tilmes S, Garcia RR, Kinnison DE, Gettelman A, Rasch PJ (2009) Impact of geoengineered aerosols on the troposphere and stratosphere. J Geophys Res Atmos 114:D12305. doi:10.1029/200 8JD011420

Tilmes et al (2013) The hydrological impact of geoengineering in the Geoengineering Model Intercomparison Project (GeoMIP). J Geophys Res Atmos 118:11036-11058. doi:10.1002/jgrd.50868

Tilmes S, Jahn A, Kay JE, Holland M, Lamarque JF (2014) Can regional climate engineering save the summer Arctic sea ice? Geophys Res Lett 41:880-885. doi:10.1002/2013GL058731

Vaughan et al (2013) Observations: cryosphere. In: Stocker TF, Qin D, Plattner GK, Tignor M, Allen SK, Boschung J, Nauels A, Xia Y, Bex V, Midgley PM (eds) Climate change 2013: the physical science basis. Contribution of Working Group I to the Fifth Assessment Report of the Intergovernmental Panel on Climate Change. Cambridge University Press, Cambridge

Voigt A, Stevens B, Bader J, Mauritsen T (2014) Compensation of hemispheric albedo asymmetries by shifts of the ITCZ and tropical clouds. J Clim 27(3):1029-1045. doi:10.1175/ JCLI-D-13-00205.1

Wang B, Ding Q (2006) Changes in global monsoon precipitation over the past 56 years. Geophys Res Lett 33(6):L06711

Wu Y, Seager R, Ting M, Naik N, Shaw TA (2011) Atmospheric circulation response to an instantaneous doubling of carbon dioxide. Part I: model experiments and transient thermal response in the troposphere. J Clim 25:2862-2878. doi:10.1175/ JCLI-D-11-00284.1

Xia L, Robock A, Tilmes S, Neely RR (2016) Stratospheric sulfate geoengineering could enhance the terrestrial photosynthesis rate. Atmos Chem Phys 16:1479-1489. doi:10.5194/ acp-16-1479-2016

Zwiers F, von Storch H (1995) Taking serial correlation into account in tests of the mean. J Clim 8:336-351 